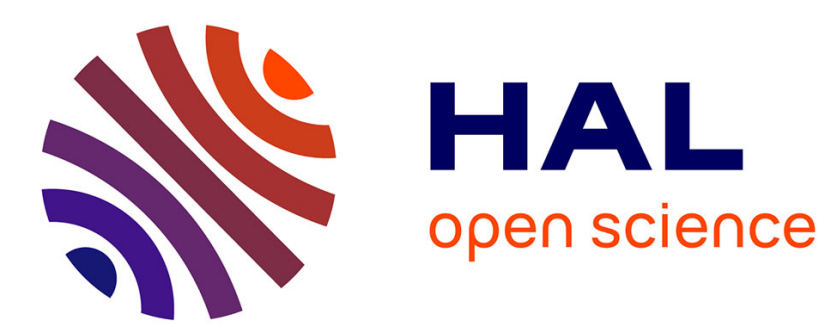

\title{
Temperature-dependent, VIS-NIR reflectance spectroscopy of sodium sulfates
}

S. de Angelis, F. Tosi, C. Carli, S. Potin, P. Beck, O. Brissaud, B Schmitt, G. Piccioni, M.C. C de Sanctis, F. Capaccioni

\section{- To cite this version:}

S. de Angelis, F. Tosi, C. Carli, S. Potin, P. Beck, et al.. Temperature-dependent, VIS-NIR reflectance spectroscopy of sodium sulfates. Icarus, 2021, 357, pp.114165. 10.1016/j.icarus.2020.114165 . hal03098451

\section{HAL Id: hal-03098451 \\ https://hal.science/hal-03098451}

Submitted on 30 Jul 2021

HAL is a multi-disciplinary open access archive for the deposit and dissemination of scientific research documents, whether they are published or not. The documents may come from teaching and research institutions in France or abroad, or from public or private research centers.
L'archive ouverte pluridisciplinaire HAL, est destinée au dépôt et à la diffusion de documents scientifiques de niveau recherche, publiés ou non, émanant des établissements d'enseignement et de recherche français ou étrangers, des laboratoires publics ou privés. 
De Angelis et al. 2021, Icarus, 357, 114165

\title{
Temperature-dependent, VIS-NIR reflectance spectroscopy of sodium sulfates
}

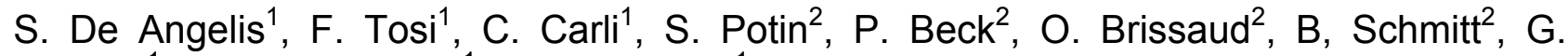 \\ Piccioni ${ }^{1}$, M.C. De Sanctis ${ }^{1}$, F. Capaccioni ${ }^{1}$ \\ ${ }^{1}$ INAF-IAPS - Institute for Space Astrophysics and Planetology - Via del Fosso del Cavaliere, 100, 00133, \\ Rome (Italy) \\ ${ }^{2}$ Université Grenoble Alpes, CNRS, Institut de Planétologie et d'Astrophysique de Grenoble (IPAG), 38058 \\ Grenoble Cédex 9, France
}

contact: simone.deangelis@inaf.it

\begin{abstract}
Hydrated sodium sulfates have been suggested to be present in variable amounts in Solar System objects such as Mars and Europa, among the possible others. The presence of these hydrated species is related to current/past aqueous environments, thus has an importance regarding the potential habitability of planetary objects. In this study, we analyzed anhydrous sodium sulfate (thénardite) and the hydrated sodium sulfate (mirabilite) by means of visible-infrared reflectance spectroscopy in the $0.4-5 \mu \mathrm{m}$ spectral range, at different low temperatures between 80 and 298K. Each mineral has been analyzed in three different grain sizes, between 36-150 $\mu \mathrm{m}$. The anhydrous compound, thénardite, is characterized by a nearly flat spectrum in the visible and near IR up to 2.6 $\mu \mathrm{m}$, while in the 3-4 $\mu \mathrm{m}$ region, the spectrum shows a few weak features due to $\mathrm{H}_{2} \mathrm{O}$ and $\mathrm{SO}_{4}{ }^{2-}$ overtones/combinations. The first strong $\mathrm{SO}_{4}{ }^{2-}$ overtone is visible at $4.6 \mu \mathrm{m}$. Spectra of mirabilite are substantially characterized by $\mathrm{H}_{2} \mathrm{O}$ absorption features in the 1-3 $\mu \mathrm{m}$ region, and by sulfate overtone/combination bands occurring at 3.8 and $4.7 \mu \mathrm{m}$. A weak feature appearing at $2.18 \mu \mathrm{m}$ is also putatively attributed to the sulfate ion. The bands show changes as a function of temperature. The hydration absorption features in mirabilite show the strongest dependence with temperature, both in terms of shift in position and change of spectral shape. Bands at 3.1-3.24 $\mu \mathrm{m}$ in thénardite, as well as absorption features located at 1.78 and $2.47 \mu \mathrm{m}$ in mirabilite, could be used as diagnostic proxies for the detection of these two minerals on planetary bodies.
\end{abstract}

\section{Introduction}

Sodium sulfates compounds occur widely on Earth in different hydration forms and in various geological settings. On other Solar System bodies they have been proposed to be present on the surface of Europa (mirabilite) and on Mars (mirabilite and thénardite).

\section{Earth}

Sulfate minerals form on Earth in several geological environments, mainly (i) as evaporitic deposits, (ii) after oxidation of sulfides in hydrothermal systems, (iii) as products of weathering of volcanic rocks (Christy, 2018). In particular evaporitic sulfate minerals are important indicators of geological evolution and past climatic conditions. They maintain a record of the source water geochemical features and of the evolution of environmental parameters driving the evaporation processes. 
The process of evaporation typically occurs from concentrated water solutions or brines, in which are present readily soluble salts. The precipitation starts after the brine becomes saturated in a given salt, and the water loss must exceed the water gain. Brines can be characterized by a wide range of ionic strength, can have multiple dissolved salts, with different solubility. The crucial parameters governing the evaporative process are temperature, humidity, air movement, salinity and pH (Babel and Schreiber, 2014). The evaporation rate is favored by high temperature, low relative humidity and air movement, while it is inhibited for example by the increase in salinity of the evaporating brine itself. On the opposite also the freezing process, by removing liquid water from the brine with consequent ice formation, can result in the precipitation of certain cryogenic sulfate salts (Babel and Schreiber, 2014; Herrero et al., 2015). With this regard, brines having eutectic temperature below $0^{\circ} \mathrm{C}$ are defined cryobrines.

Specifically thénardite and mirabilite occur on Earth both in open and closed basins, that are in marine and lacustrine evaporitic deposits (Jones and Deocampo, 2003; Babel and Schreiber, 2014). The mineralogy of precipitated compounds depends on the composition of the salts dissolved in the brine, and on the proportions between ions, as well as on the driving process (evaporative or cooling/freezing). Brines that can result in the precipitation of thénardite and mirabilite are of three types: (i) $\mathrm{Na}-\mathrm{CO}_{3}-\mathrm{SO}_{4}-\mathrm{Cl}-(\mathrm{K})$, (ii) $\mathrm{Na}-\mathrm{SO}_{4}-\mathrm{Cl}-(\mathrm{K}$ ) and (iii) Mg-Na-SO ${ }_{4}-\mathrm{Cl}-(\mathrm{K})$ (Eugster, 1980; Warren, 2006). Na-sulfate salts (anhydrous and hydrated) are generally found in the same environment. Thénardite and mirabilite can crystallize from brines in which $\mathrm{HCO}_{3}{ }^{-}$exceeds $\mathrm{Ca}^{2+}$ : that is in carbonate-rich, calciumpoor, sulfate-enriched waters, so that Ca-sulfates cannot form (Hardie and Eugster, 1970; Jones and Deocampo, 2003).

Sodium sulfates are strongly temperature dependent: on Earth, the anhydrous form thénardite typically is formed in hot and arid climatic conditions, while mirabilite is a typical product of cool periods (Herrero et al., 2015). Thus thénardite is found on Earth both in recent and in ancient deposits, as primary precipitation product of warm brines in shallow lakes or as efflorescent crust in playa environments (Herrero et al., 2015). Mirabilite instead is not found in ancient environments: this is due to its high reactivity and sensitivity to temperature changes, as it readily can dehydrate and transform to thénardite. The process of transformation of mirabilite to thénardite is temperature dependent: the dehydration occurs at $32^{\circ} \mathrm{C}$, in presence of $\mathrm{NaCl}$ it occurs at $18^{\circ} \mathrm{C}$, while it drops down to $16^{\circ} \mathrm{C}$ in presence of $\mathrm{Mg}^{2+}$ ions (Herrero et al., 2015). Transformation of mirabilite to thénardite also depends on relative humidity (Steiger and Asmussen, 2008). Secondary thénardite can be formed as a consequence of diagenesis of other minerals, typically mirabilite dehydration. Both thénardite and mirabilite however can precipitate during evaporative (high temperature) and cooling/freezing (cryogenic) processes. Precipitation of mirabilite from a cooling brine starts at lower temperatures as its concentration decreases. On Earth, mirabilite mounds have been also found in Antarctica, and interpreted as evaporative/freezing precipitation products in subglacial environments (Socki et al., 2012).

\section{Mars}

The identification of sulfates, both anhydrous and hydrated, on Martian surface, is important in order (i) to infer clues about the amount of water bound in regolith and rocks, and (ii) to better understand the past climatic evolution. Sulfates on Mars are interpreted to be formed as (i) primary evaporite minerals or as (ii) secondary weathering products. 
Sodium sulfates have been inferred to be present on Mars on the basis of geochemical modeling and chemical composition measurements. Anhydrous and monohydratedpolyhydrated sulfates, hosting various types of cations (mostly $\mathrm{Ca} / \mathrm{Fe} / \mathrm{Mg}$ ), have been detected at different locations on Mars by remote-sensing VIS-NIR spectroscopy with Observatoire pour la Minéralogie, l'Eau, les Glaces et l'Activité (OMEGA) onboard Mars Express and the Compact Reconnaissance Imaging Spectrometer for Mars (CRISM) onboard Mars Reconnaissance Orbiter instruments, and reported by a vast literature (Gendrin et al., 2005; Murchie et al., 2009; Mangold et al., 2008; Flahaut et al., 2014).

On the basis of OMEGA spectral data, hydrated Na-sulfates could be present in the West Chandor Chasma within Valles Marineris (Mangold et al., 2008). Sulfur-bearing compounds are thought to be present at the Mars Pathfinder landing site based on alpha proton X-ray spectrometer (APXS) data (Foley et al., 2003). In particular, thénardite and mirabilite have been suggested to be present at the Mars Pathfinder landing site: according to the strong correlation found between $\mathrm{Na}_{2} \mathrm{O}$ and $\mathrm{SO}_{3}, \mathrm{Na}_{2} \mathrm{SO}_{4}$ is likely to be present in rock samples and in rock-weathering crusts, while it is less likely to be present in soil (Zolotov et al., 2004). Sulfur-bearing compounds have also been inferred to be present at Meridiani Planum by APXS instrument onboard MER Opportunity rover (Brueckner et al., 2009). Analyzing the 6.1- $\mathrm{mm}$ bound-water band in Thermal Emission Spectrometer (TES/Mars Global Surveyor) spectra, Kuzmin et al. (2004) suggested the presence of Na-sulfates in belts surrounding the ice in the polar caps, subject to seasonal cycles of hydration/dehydration. Moreover, sodium sulfates are predicted to be present according to modeling of chemical divides applicable to Martian evaporating brines, characterized by acidic conditions more than on Earth (Tosca and McLennan 2006).

\section{Europa}

The data from Galileo Near-Infrared Mapping Spectrometer (NIMS) led to the prevailing view that Europa's endogenous units are rich in sulfate salts (McCord et al., 1998a, 1998b, 1999, 2010, Dalton, 2007). The deca-hydrated form of sodium sulfate (mirabilite) has been initially proposed as one of the candidate materials for the heavily hydrated salts, thought to constitute the "non-icy" regions of the trailing hemisphere of Europa, on the basis of Galileo/NIMS VIS-IR spectral data (McCord et al., 1998a, 1998b, 1999, 2010). The occurrence of heavily hydrated salts on the surface of Europa was initially suggested because of the distorted spectral shape of hydration bands at 1.5 and $2 \mu \mathrm{m}$ in NIMS data, notably different from more symmetric pure water ice absorption bands; nevertheless the same spectral data were also interpreted with the presence of hydrated sulfuric acid of logenic origin (Carlson et al., 2009) and more recently with Mg-bearing chlorinated salts (Ligier et al., 2016). Vu et al. (2016) suggest, on the basis of experimental measurements of frozen brines, that mirabilite and $\mathrm{MgCl}_{2}$ are expected to precipitate on the surface upon ocean freezing. The presence of hydrated salts on the surface of Europa, of endogenic origin, could be evidence of rising of materials from the ocean below the icy crust, with consequent deposition on surface after brines sublimation. This has consequences for understanding the dynamics and chemical mixing within the liquid ocean and then astrobiological implications.

\section{Previous laboratory studies}

Several authors have studied sulfates in laboratory, by means of VIS-IR reflectance spectroscopy, although very few investigated sodium sulfates. The first study to report infrared reflectance spectra of sulfates was the work by Omori and Kerr (1963). In their study they reported infrared spectra of a great number of anhydrous and hydrous sulfates, 
including thénardite: spectra were acquired in the 2-15 $\mu \mathrm{m}$ range at room P-T conditions. Crowley (1991) measured VIS-NIR spectra $(0.4-2.5 \mu \mathrm{m})$ of tens of playa evaporite minerals, in particular also thénardite and mirabilite. Spectra were acquired on coarse powders $(250 \mu \mathrm{m})$ and at room P-T conditions, after drying at $60^{\circ} \mathrm{C}$ for few minutes. Thénardite was also measured by Vassallo and Finnie (1992) in the mid-IR range in emissivity, at temperatures $>50^{\circ} \mathrm{C}$. McCord et al. (2001) investigated three heavily hydrated minerals, including mirabilite, in the IR range 1-2.7 $\mu \mathrm{m}$, in vacuum and in the temperature range $100-375 \mathrm{~K}$. Dalton et al. (2005) measured spectra of mirabilite in the 0.35-2.5 $\mu \mathrm{m}$ range in the 50-250K temperature interval. Cloutis et al. (2006) investigated by reflectance spectroscopy a large number of sulfates in a broad IR range, although they did not study Na-sulfates. Bishop et al. (2015) and Flahaut et al. (2017) studied evaporite assemblages in Chilean salars, by means of field VIS-NIR spectroscopy, including mirabilite. Thus most of studies have focused on the VIS-NIR spectra of sodium sulfates, or typically at ambient temperature. Spectra in the $>2.5-\mu \mathrm{m}$ region at cryogenic temperatures are lacking, as well as spectra of samples with different grain sizes.

\section{Methods}

\subsection{Experimental setup}

The spectral measurements were performed at the Institute de Planétologie et d'Astrophysique de Grenoble (IPAG), with the SHINE Spectro-Gonio Radiometer facility (Brissaud et al., 2004). Reflectance spectra were acquired in the Visible-Near Infrared (VIS-NIR) range 0.4-5.0 $\mu \mathrm{m}$, using a monochromator light source. The spectral range is covered thanks to a Si-diode $(\lambda<1 \mu \mathrm{m})$ and an InSb detector $(\lambda>1 \mu \mathrm{m})$. Optical fibers mounted on the goniometer arms permit homogeneous illumination of the sample and collection of the reflected light within a narrow solid angle. Data were acquired with a constant spectral sampling of $20 \mathrm{~nm}$ and a spectral resolution varying between 5 and 38 $\mathrm{nm}$ (value increasing, i.e. worsening, by about a factor 2 at each grating change with increasing wavelength) across the whole range.

The samples to be measured were put in an aluminum sample holder cup, with diameter $48 \mathrm{~mm}$ and $>5 \mathrm{~mm}$ deep; the cup is mounted within the CarboN-IR environmental cell, purged with gas $\mathrm{N}_{2}$ flux at 1 bar atmosphere. This internal cell is placed inside an external cell, in which high vacuum is performed (Grisolle 2013; https://coldspectro.sshade.eu/carbo-nir-simulation-chamber).

Measurements were carried out at 12 different temperatures in the overall $80-298 \mathrm{~K}$ range, at steps varying from 10 to $25 \mathrm{~K}$, using a ${ }^{4} \mathrm{He}$ Stirling cycle-cryostat and a Lakeshore temperature controller with $+/-0.1 \mathrm{~K}$ error. Once a given temperature was reached, the data acquisition started after 5 minutes to allow for thermal stabilization of the sample.

The instrument usage, temperature control and data acquisition and calibration were managed through LabVIEW procedures developed at IPAG (Potin et al., 2018).

\subsection{Samples}

Two mineral samples were analyzed, namely anhydrous sodium sulfate, $\mathrm{Na}_{2} \mathrm{SO}_{4}$ (thénardite) and sodium sulfate decahydrate, $\mathrm{Na}_{2} \mathrm{SO}_{4} \bullet 10 \mathrm{H}_{2} \mathrm{O}$ (mirabilite). The compounds were purchased on the market from Sigma Aldrich, and certified with $>99 \%$ purity. Each mineral was measured in three different grain size ranges: 36-50 $\mu \mathrm{m}, 75-100 \mu \mathrm{m}$ and 125$150 \mu \mathrm{m}$. The grain size ranges were chosen in order to be representative of planetary regoliths in the fine, medium and coarse regime, and in such a way to avoid overlapping 
among them. The mineral powders were produced starting from coarse fragments, by grinding with agate mortar and sieving. This preparation was done at Sample Preparation Facility at IAPS-INAF. The nominally anhydrous sample (thénardite) was stored at IPAG for several days before measurements in a desiccator cabinet under controlled humidity, with the goal of minimizing the amount of adsorbed room water vapour.

\subsection{Acquisitions and data treatment}

Measurements were carried out at 12 different temperatures in the overall $80-298 \mathrm{~K}$ range, at increasing steps of 10 to $25 \mathrm{~K}$, on all samples and grain sizes. For each sample, the measurement cycle was: (i) first acquisition at room temperature (varying between 275$304 \mathrm{~K}$ ), called "T-down", (ii) cooling down the sample to $80 \mathrm{~K}$, (iii) acquisitions at the selected temperatures during the warming up of the sample, up to room temperature (the latter called "T-up"). In some case the spectra at $140 \mathrm{~K}$ were taken both during the cooling and warming phases, to check for any potential, macroscopic physico-chemical changes in the sample.

LabSphere $^{\odot}$ Spectralon and Infragold were acquired in air outside the cell as reference targets, to cover the spectral range $<2 \mu \mathrm{m}$ and $>2 \mu \mathrm{m}$ respectively. In the calibration procedure, a photometric correction that takes into account the contribution of the optical window is applied.

Data analyses were carried out by using a LabVIEW tool for spectral fitting developed at IAPS. Spectral parameters were retrieved for each analyzed absorption band, for all samples. The analyzed parameters were: (i) band position, (ii) depth, (iii) area and (iv) width. The position was computed after continuum removal: the continuum was calculated as a straight line between the wavelength edges $\left(\lambda_{i}-\lambda_{f}\right)$ of each main band; after dividing the spectrum by the continuum line, the band position $\left(B_{C}\right)$ was calculated by using three different approaches: (a) taking the minimum value of reflectance; (b) by locally fitting data around the minimum with a spline curve, whose minimum yields the band center; (c) fitting around the minimum with a second degree polynomial. We used the method (c) for well defined bands containing a sufficiently high number of sampling points. For weak bands poorly sampled, we used the approaches (a) and (b). The band depth $\left(B_{D}\right)$ was computed according to the formula (Clark \& Roush, 1984):

$$
B_{D}=1-\frac{R_{B}}{R_{C}}
$$

in which $R_{B}$ is the reflectance at the band center and $R_{C}$ is the interpolated value of the spectral continuum at the same wavelength. The band area $\left(B_{A}\right)$ parameter is computed, after continuum removal, with the following formula:

$$
B_{A}=A_{R}-I_{B}
$$

where $A_{R}$ is the rectangular area comprised between $\lambda_{i}-\lambda_{f}$ and $R=1$, and $I_{B}$ is the integral defined between $\lambda_{l}$ and $\lambda_{f}$, which delimits the band. Finally, the band width $\left(B_{W}\right)$ is computed as the Full Width at Half Maximum corresponding to the band center. In order to evaluate the variability of such parameters and to provide an estimate of the errors, the procedure for the retrieval of parameters has been repeated four times, each time making the $\lambda_{i}-\lambda_{f}$ to vary by $\pm 20 \mathrm{~nm}$, i.e. slightly changing the position of the anchor points of the continuum line 


\section{Results}

\subsection{Spectral measurements}

In this section we describe the spectral data acquired on the two sulfate salts in a broad range of temperatures (Fig. 1 and 2). For each sulfate, we separately show the spectra of the three grain sizes (De Angelis et al., 2018a, 2018b) (fig.3).

\subsubsection{Anhydrous sodium sulfate}

The spectra of thénardite acquired at different temperatures are shown in Fig.1 for the three considered grain sizes. The spectra are flat, featureless and slightly red-sloped up to $<2.5 \mu \mathrm{m}$. A very weak absorption band near $2 \mu \mathrm{m}$ and a broad one at $3 \mu \mathrm{m}$ testify the presence of some water adsorbed in the grains, although the nominally anhydrous sample was stored in a desiccator cabinet with low humidity days before the measurements, and only a few minutes passed between the extraction of the powder and its positioning in the cell for analyses. This happens because this sample is very hygroscopic. However, it should be considered that this water band is due to fundamental vibration modes of the molecule and has thus a very high absorption coefficient making it to appears even with very low amounts of adsorbed water, $<<1$ wt\% (Salisbury \& Walter, 1989; Pommerol et al. 2009). Absorption features due to adsorbed water are reported at wavelengths 1.41 and $1.92 \mu \mathrm{m}$ (Crowley, 1991). The feature appearing at $2.6 \mu \mathrm{m}$ is due to the presence of a fluctuating amount of water vapour in the room that is not perfectly compensated with the calibration reference. A number of absorption bands occur in the 3-4 $\mu \mathrm{m}$ range. These bands are centered at 3.1,3.2, 3.42-3.50, 3.68 and $3.86 \mu \mathrm{m}$. The features appearing at 3.1 and $3.2 \mu \mathrm{m}$ are likely due to the presence of water in the sample [Cloutis et al., 2006], although these two bands are observed also in other sulfates (Bishop et al., 2014). The two minima at 3.42-3.5 $\mu \mathrm{m}$ seem to belong to a single, broader band. These features are not strictly vibrations of the sulfate; rather they could be related to vibration modes of water molecules linked to the sulfate. Alternatively this feature could be due to $\mathrm{C}-\mathrm{H}$ vibration, putatively from organic contamination. Indeed also a very small amount $(<1 \%)$ of organic contamination occurred during the sample preparation or measurement could be responsible of such band. Few literature data exist relative to the bands at 3.68 and 3.86 $\mu \mathrm{m}$. A band at $3.87 \mu \mathrm{m}$, attributed to overtone or combination of $\mathrm{SO}_{4}{ }^{2-}$ fundamental modes, is reported for the mineral coquimbite while for other sulfates this band is reported to be near $4.0 \mu \mathrm{m}$ [Cloutis et al., 2006]. The fundamental vibrations of $\mathrm{SO}_{4}{ }^{2-}$ are located near $9 \mu \mathrm{m}$ (symmetric and asymmetric stretching at 981 and $1104 \mathrm{~cm}^{-1}$ [Bishop \& Murad, 2005]). In the 4-5 $\mu \mathrm{m}$ region several overtone/combination modes of S-O occur [Bishop \& Murad, 2005; Cloutis et al., 2006]. The first overtone of such fundamental band occurs near $4.6 \mu \mathrm{m}$. This appears as a broad and intense doublet of bands, with minima near 4.45 and $4.6 \mu \mathrm{m}$, separated by an interband peak (minimum of absorption) at $4.53 \mu \mathrm{m}$. The minima in these bands become less sharp and more flattened with increasing grain size. In the coarser grain size the band is almost saturated and minima are no longer discernible (fig.1).

\subsubsection{Sodium sulfate decahydrate}

The spectra of sodium sulfate decahydrate (mirabilite) are shown in Fig. 2. Spectra are flat and featureless in the visible range up to $1 \mu \mathrm{m}$. The slope in this range tends to become bluer (negative) with increasing grain size and decreasing temperature. Several absorption 
bands occur in the IR range 1-5 $\mu \mathrm{m}$, most of them being due to structural $\mathrm{H}_{2} \mathrm{O}$ molecules in the hydrated mineral. Hydration absorption features occur at ambient temperature near $1.2,1.46,1.78,1.96,2.47$, and $3.0 \mu \mathrm{m}$. A weak $\mathrm{H}_{2} \mathrm{O}$ band appears at $1 \mu \mathrm{m}$ in the medium $(75-100 \mu \mathrm{m})$ and coarse grain size $(125-150 \mu \mathrm{m})$ spectra. On the high wavelength side of the 1.46- $\mu \mathrm{m}$ band, several minima appear as inflections at the lowest temperatures. In the $2-\mu \mathrm{m}$ complex a secondary feature shows up near $2.2 \mu \mathrm{m}$. All these features are related to overtones and combinations of fundamental vibrational modes of the high number of water molecules within the mineral [Cloutis et al., 2006]. These absorption features are also consistent with measurements by Crowley (1991): in the 2.2- $\mu \mathrm{m}$ region he reports two features centered at 2.18 and $2.24 \mu \mathrm{m}$. The 2.47- $\mu \mathrm{m}$ feature can be due to a combination/overtone of stretching and bending modes of $\mathrm{H}_{2} \mathrm{O}$ or to the $3 v_{3}$ overtone of the fundamental asymmetric bending mode of $\mathrm{SO}_{4}{ }^{2-}\left(v_{3}, 7.8-10.4 \mu \mathrm{m}\right)$ [Cloutis et al., 2006]; nevertheless, the circumstance that this band only appears in the hydrated sample and not in the anhydrous one, could be an indication of a water origin. Two other bands appear at $3.8 \mu \mathrm{m}$ and $4.6 \mu \mathrm{m}$, both related to overtone/combinations of S-O fundamental modes. The first is weak and only visible at the lowest temperatures $(T<140 \mathrm{~K})$, while the second is very broad and intense, with its long-wavelength edge occurring beyond $5 \mu \mathrm{m}$. The features appearing in the 4-5 $\mu \mathrm{m}$ region are interpreted as first-order overtones and combinations of the fundamental asymmetric bending mode $v_{3}$ of $\mathrm{SO}_{4}{ }^{2-}$ (Cloutis et al., 2006). The 1.20 and 1.46- $\mu \mathrm{m}$ bands are not/partially visible in 80 and $205 \mathrm{~K}$ spectra of the 36-50 grain size, respectively, due to instrumental artifacts occurred during this acquisition in the 1.1-1.4- $\mu \mathrm{m}$ spectral range. 

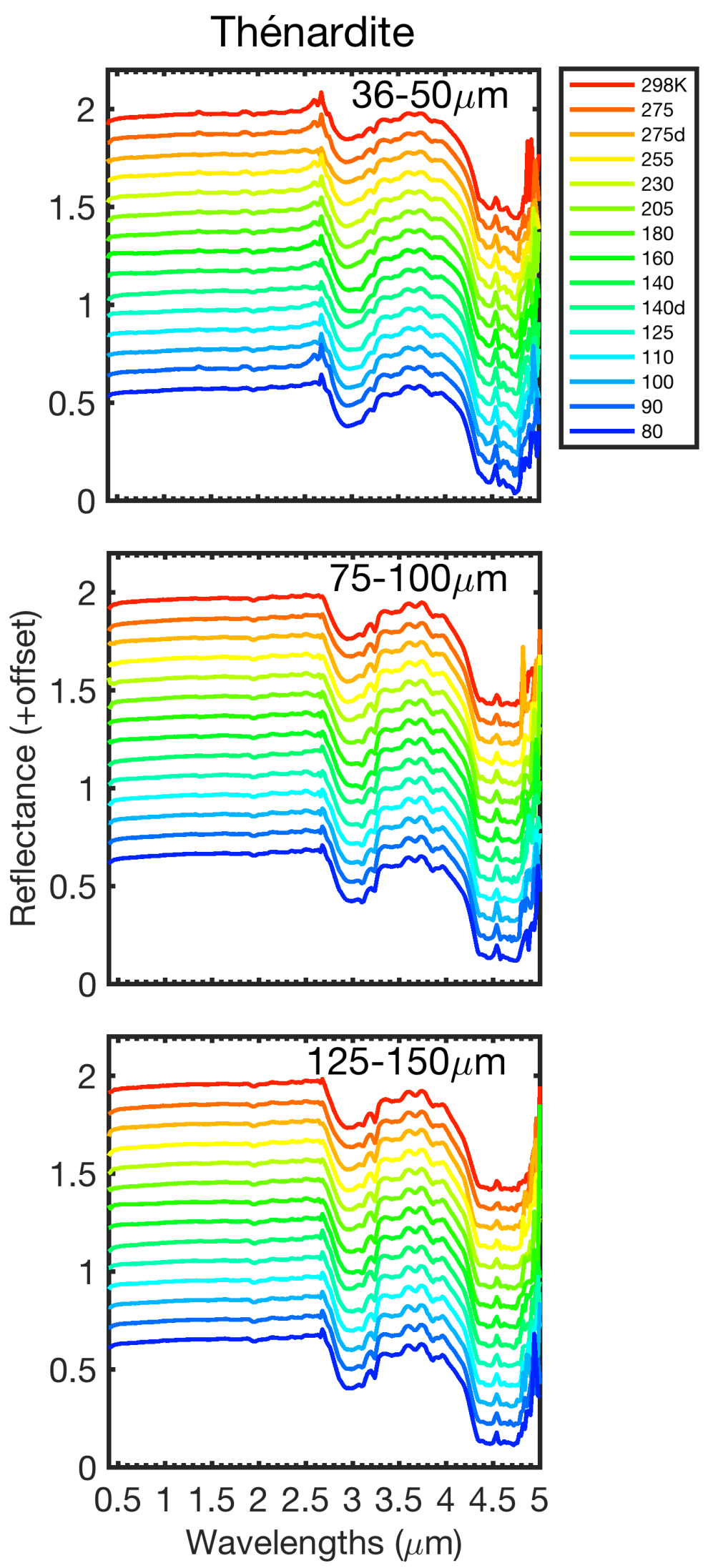

Fig.1. Reflectance spectra of anhydrous sodium sulfate (thénardite), measured at different temperatures in the range $80-298 \mathrm{~K}$ and in three grain sizes. Temperatures decrease from top to bottom. Top panel: "fine" grain size (36-50 $\mu \mathrm{m})$. Middle panel: "intermediate" grain size (75-100 $\mu \mathrm{m})$. Bottom panel: "coarse" grain size $(125-150 \mu \mathrm{m})$. Spectra above $80 \mathrm{~K}$ are shifted vertically by 0.1 in reflectance for clarity. 

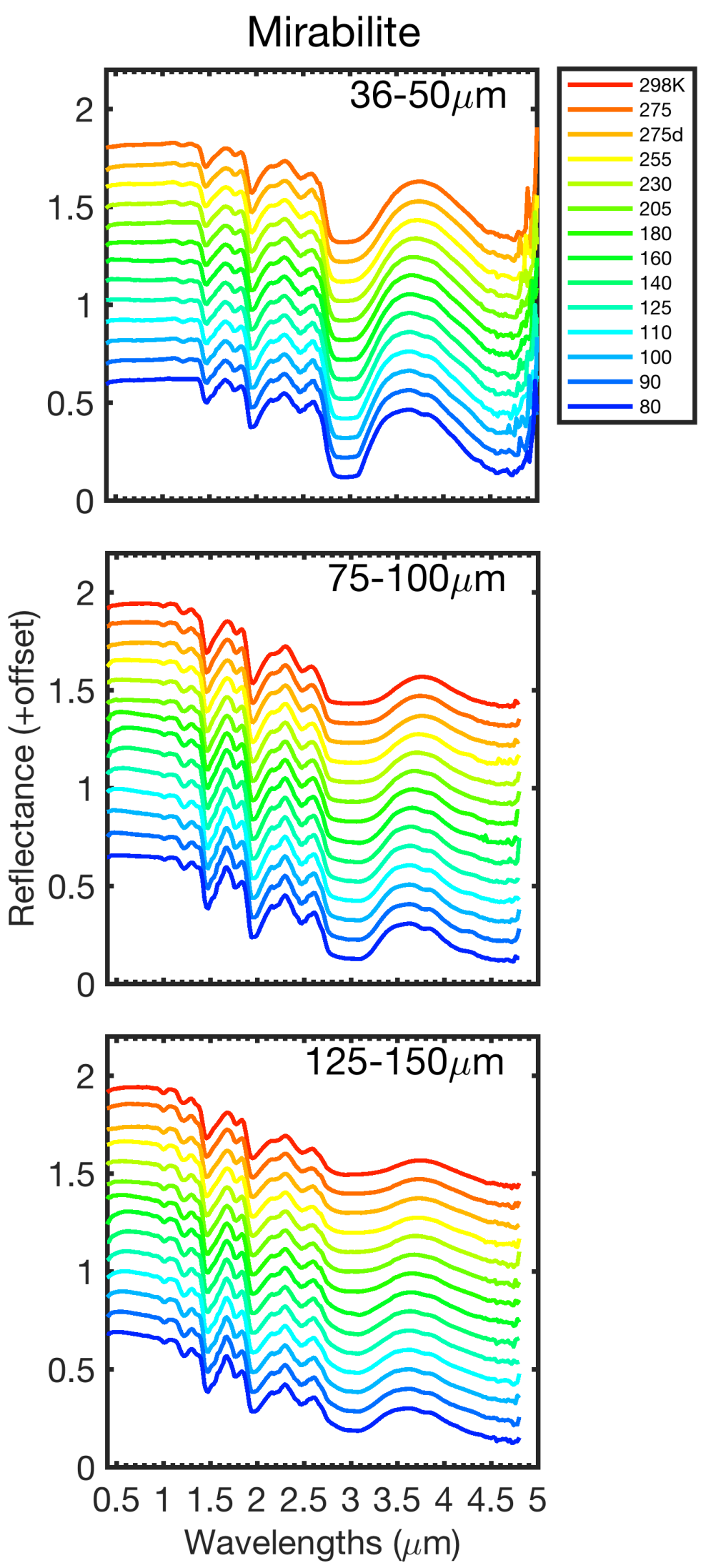

Fig. 2. Reflectance spectra of decahydrated sodium sulfate (mirabilite), measured at different temperatures in the range $80-298 \mathrm{~K}$ and in three grain sizes. Temperatures decrease from top to bottom. Top panel: "fine" grain size (36-50 $\mu \mathrm{m})$. Middle panel: "intermediate" grain size (75-100 $\mu \mathrm{m})$. Bottom panel: "coarse" grain size $(125-150 \mu \mathrm{m})$. Spectra above $80 \mathrm{~K}$ are shifted vertically by 0.1 in reflectance for clarity. 


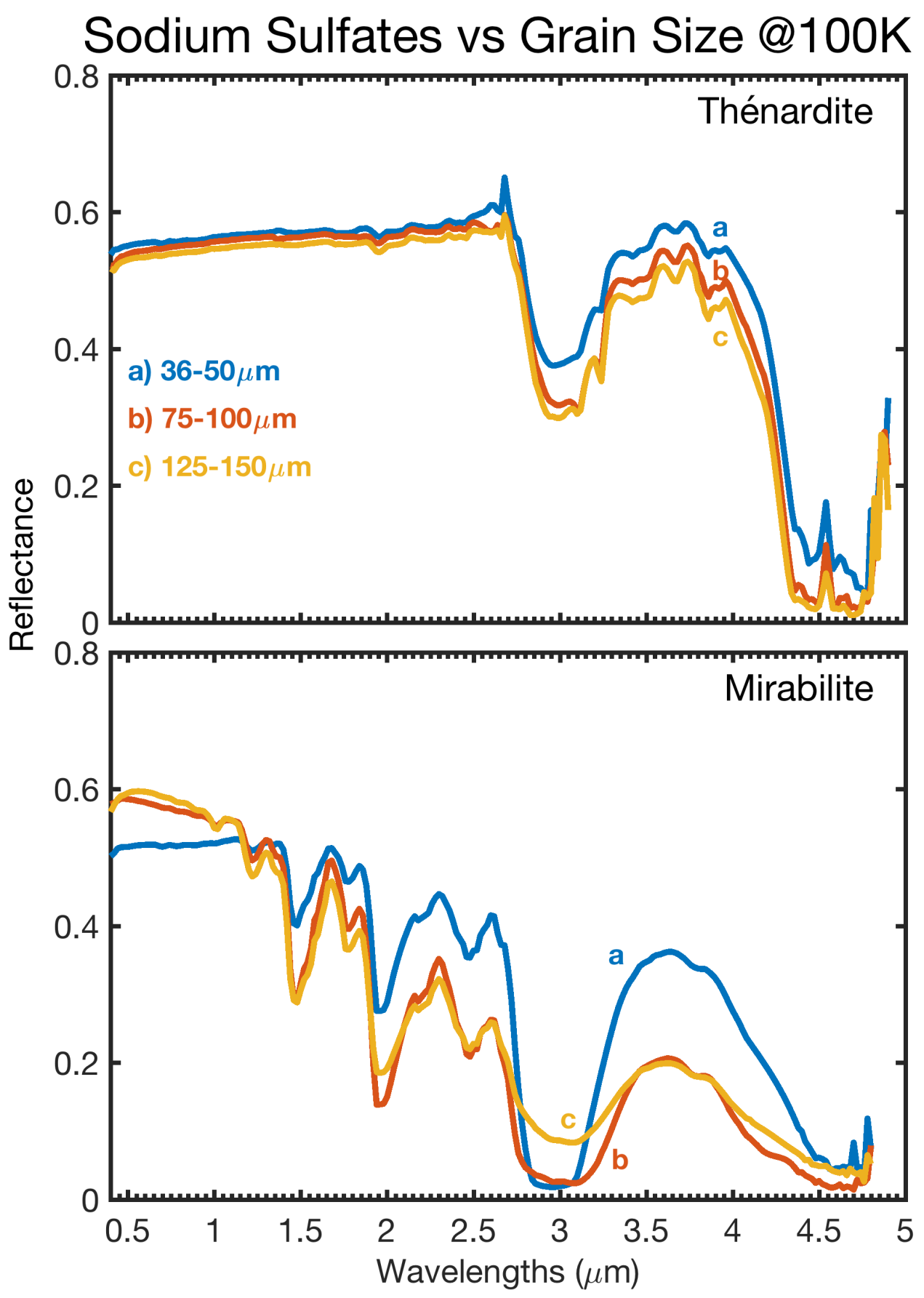

Fig. 3. Reflectance spectra of thénardite (top) and mirabilite (bottom) for the three analyzed grain sizes. For each grain size two temperatures are shown, $80 \mathrm{~K}$ and $298 \mathrm{~K}$.

\subsection{Spectral analysis}

In this section we report the results of the spectral analysis carried out for the two sulfate compounds described in this paper, according to the procedures for parameters retrieval described in Section 2. The four parameters have been calculated at all measured temperatures with the aim to highlight their temperature dependence. In Table 1, we list all the identified spectral features for the two sulfates, with information about their assignment, when known, and about the analyses. In the following we only present and discuss parameters that display significant trends as a function of temperature. The 
continuum-removed bands are shown in Fig. 4-5 for thénardite and in Fig. 7 for mirabilite. Regarding the thénardite, none of the absorption features displayed by the nominally anhydrous compound show any significant wavelength-dependence on temperature, at least at the spectral resolution of the measurements, except the $3-\mu \mathrm{m}$ water band, which is due to water adsorption as explained in the previous section.

\begin{tabular}{|c|c|c|c|c|c|}
\hline Sample & Band $(\mu \mathrm{m})$ & Band $\left(\mathrm{cm}^{-1}\right)$ & Origin & Strength & Analysis \\
\hline \multirow{10}{*}{$\begin{array}{l}\text { Thénardite } \\
\left(\mathrm{Na}_{2} \mathrm{SO}_{4}\right)\end{array}$} & 1.9 & 5263 & $\mathrm{H}_{2} \mathrm{O}$ combination ${ }^{(1)}$ & vw & \\
\hline & 2.6 & 3846 & $\mathrm{H}_{2} \mathrm{O}$ (vapour) & w & \\
\hline & $2.9-3.0$ & $3448-3333$ & $\mathrm{H}_{2} \mathrm{O}$ stretching+bending & vs & $\mathrm{X}$ \\
\hline & 3.1 & 3226 & $\mathrm{H}_{2} \mathrm{O}$ & $\mathrm{m}$ & $\mathrm{X}$ \\
\hline & 3.24 & 3086 & $\begin{array}{l}\mathrm{H}_{2} \mathrm{O} \text { or } \mathrm{SO}_{4}{ }^{2-} \\
\text { overtone/combination }{ }^{(2)}\end{array}$ & $\mathrm{m}$ & $\mathrm{X}$ \\
\hline & $3.42(\mathrm{I})-3.50(\mathrm{II})$ & $2924-2857$ & $\begin{array}{l}>\mathrm{H}_{2} \mathrm{O} \text { combination } \\
>\quad \mathrm{C}-\mathrm{H} \text { stretch } \\
\end{array}$ & $\mathrm{m}$ & $\mathrm{X}$ \\
\hline & 3.68 & 2717 & $\begin{array}{l}>\mathrm{SO}_{4}{ }^{2-} \mathrm{S}-\mathrm{O} \text { overtone / } \\
\text { combination? }\end{array}$ & $\mathrm{m}$ & $\mathrm{X}$ \\
\hline & 3.86 & 2591 & $\begin{array}{l}\mathrm{SO}_{4}{ }^{2-}[\mathrm{S}-\mathrm{O} \text { overtone / } \\
\left.\text { combination }{ }^{(6)}\right]\end{array}$ & $\mathrm{m}$ & $\mathrm{X}$ \\
\hline & 4.2 & 2381 & $\mathrm{CO}_{2}$ (gas) & $\mathrm{s}$ & \\
\hline & $4.4(\mathrm{I})-4.7$ (II) & $2273-2128$ & $\begin{array}{l}\mathrm{SO}_{4}{ }^{2-}[\mathrm{S}-\mathrm{O} \text { overtone / } \\
\left.\text { combination }{ }^{(6)}\right]\end{array}$ & vs & $\mathrm{X}$ \\
\hline \multirow[t]{10}{*}{$\begin{array}{l}\text { Mirabilite } \\
\left(\mathrm{Na}_{2} \mathrm{SO}_{4} \cdot 10 \mathrm{H}_{2} \mathrm{O}\right)\end{array}$} & 1.0 & 10000 & $\begin{array}{l}\mathrm{H}_{2} \mathrm{O} \text { (medium + coarse grain } \\
\text { size) }\end{array}$ & w & \\
\hline & 1.2 & 8333 & $\mathrm{H}_{2} \mathrm{O}$ & w & $\mathrm{X}$ \\
\hline & 1.46 (+ 1.55 shouder $)$ & 6849 & $\mathrm{H}_{2} \mathrm{O}$ - complex & $\mathrm{s}$ & $\mathrm{X}$ \\
\hline & 1.78 & 5618 & $\begin{array}{l}\mathrm{H}_{2} \mathrm{O} \text { [reported in hydrated } \\
\left.\text { sulfates }{ }^{(6)}\right]\end{array}$ & $\mathrm{m}$ & $\mathrm{X}$ \\
\hline & 1.95 & 5128 & $\mathrm{H}_{2} \mathrm{O}$ combination & $\mathrm{s}$ & $\mathrm{X}$ \\
\hline & 2.18 & 4587 & $\begin{array}{l}3 v_{3} \mathrm{~S}-\mathrm{O} \text { or } \mathrm{H}_{2} \mathrm{O} \text { combinations } \\
\text { and/or overtones }\end{array}$ & VW & \\
\hline & 2.47 (triplet) & 4049 & $\begin{array}{l}\text { Combination of } \mathrm{H}_{2} \mathrm{O} \text { stretching } \\
\text { or bending }\end{array}$ & $\mathrm{m}$ & $\mathrm{X}$ \\
\hline & 3.0 & 3333 & $\mathrm{H}_{2} \mathrm{O}$ stretching+bending & vs & $\mathrm{X}$ \\
\hline & 3.8 & 2632 & $\begin{array}{l}\mathrm{SO}_{4}{ }^{2-}[\mathrm{S}-\mathrm{O} \text { overtone } / \\
\left.\text { combination }{ }^{(6)}\right]\end{array}$ & w & $\mathrm{X}$ \\
\hline & 4.6 doublet & 2174 & $\begin{array}{l}\mathrm{SO}_{4}{ }^{2-}[\mathrm{S}-\mathrm{O} \text { overtone / } \\
\left.\text { combination }^{(6)}\right]\end{array}$ & vs & $\mathrm{X}$ \\
\hline
\end{tabular}

Tab.1. Spectral features identified in spectra of the two measured compounds. Acronyms for the band strength are: $v w=$ very weak; $w=$ weak; $m=$ medium; $s=$ strong; $v s=$ very strong. References cited in the table are: (1) Clark et al., 1990; (2) Bishop et al., 2014; (2) Bishop et al., 1996; (2) Bishop et al., 1998; (2) Bishop et al., 2001; (6) Cloutis et al., 2006; (7) Crowley, 1991.

\subsubsection{Anhydrous sodium sulfate}

\section{3- $\mu m$ band}

Spectral parameters retrieved for the 3- $\mu \mathrm{m}$ complex (Fig. 4) are shown in Fig. 6. For this feature, we computed the band area and the band width between the wavelengths 2.65$3.55 \mu \mathrm{m}$. Depth and area increase rather linearly as the temperature decreases, down to about $150 \mathrm{~K}$, then the values of these two parameters tend to sligthly decrease. The band position shows a nonlinear behavior as the temperature decreases: first it shifts from 2.95$2.96 \mu \mathrm{m}$ (depending on grain size) towards shorter wavelengths, then it moves to longer wavelengths, it reaches a maximum at about $2.99 \mu \mathrm{m}$, then it goes back again to shorter wavelengths. For each grain size, the overall shift in the band center from the minimum value to the maximum value is about $40 \mathrm{~nm}$. The maximum value is achieved at $150 \mathrm{~K}$. 
The effect of grain size is different for the various parameters. The band position appears to be substantially shifted towards longer wavelengths for the "intermediate" grain size (75$100 \mu \mathrm{m})$ and towards shorter wavelengths for the "fine" grain size (36-50 $\mu \mathrm{m})$; the "coarse" grain size $(125-150 \mu \mathrm{m})$ being an intermediate case. Depth and area increase monotonically with grain size.

The $3.1 \mu \mathrm{m}$ and $3.24 \mu \mathrm{m}$ bands due to $\mathrm{H}_{2} \mathrm{O}$ show a behavior similar to the previous feature (fig.6); there is not any evident wavelength shift with temperature $(<<5 \mathrm{~nm})$, the depth increases up to a maximum value (for $T=150 \mathrm{~K}$ ) and then it decreases very slightly as the temperature keeps on decreasing. Area and width behaviour with temperature are the same as for the $3 \mu \mathrm{m}$ band.

\section{3-4- $\mu$ m region}

The 3.4- $\mu \mathrm{m}$ feature, characterized by two minima at 3.42 and $3.5 \mu \mathrm{m}$, is consistent with the presence of very small amounts of $\mathrm{C}-\mathrm{H}$ compounds $(<1 \%)$ in the sample, given its similarity in terms of band position and shape to $\mathrm{C}-\mathrm{H}$ features typically occurring in natural materials (Bishop et al., 1996, 1998, 2001).

Band parameters for the small features at 3.68 and $3.86 \mu \mathrm{m}$ (Fig. 4) are shown in Fig. 1A (Online Supplementary Material). They are both characterized by a slight increase of band depth and area with decreasing temperatures; this effect is more marked at greater grain sizes. The position of features appear to be constant (within $<2 \mathrm{~nm}$ ) with temperature change. The effect of grain size is clear on depth and area: these parameters have larger values with increasing grain size.

\section{6- um band doublet}

The continuum-removed band is displayed in Fig. 5 for the three grain sizes. Band parameters have not been retrieved for the sulfate $4.6-\mu \mathrm{m}$ band doublet, because data beyond $4.8 \mu \mathrm{m}$ are affected by a very low signal-to-noise ratio; for this reason, the band is incomplete and it was impossible to fix unambiguously the right edge wavelength for the continuum removal. Nevertheless, the effect of temperature is visible especially for the intermediate grain size: the band becomes narrower for decreasing temperature, with the interband $4.5-\mu \mathrm{m}$ peak height increasing while temperature decreases. The effect of grain size is also rather clear: the bottom of the two components of the band becomes flatter, due to their saturation, and the slope decreases as the grain size gets larger (fine $\rightarrow$ medium $\rightarrow$ coarse). The absolute height of the interband peak at $4.53 \mu \mathrm{m}$ also decreases. 


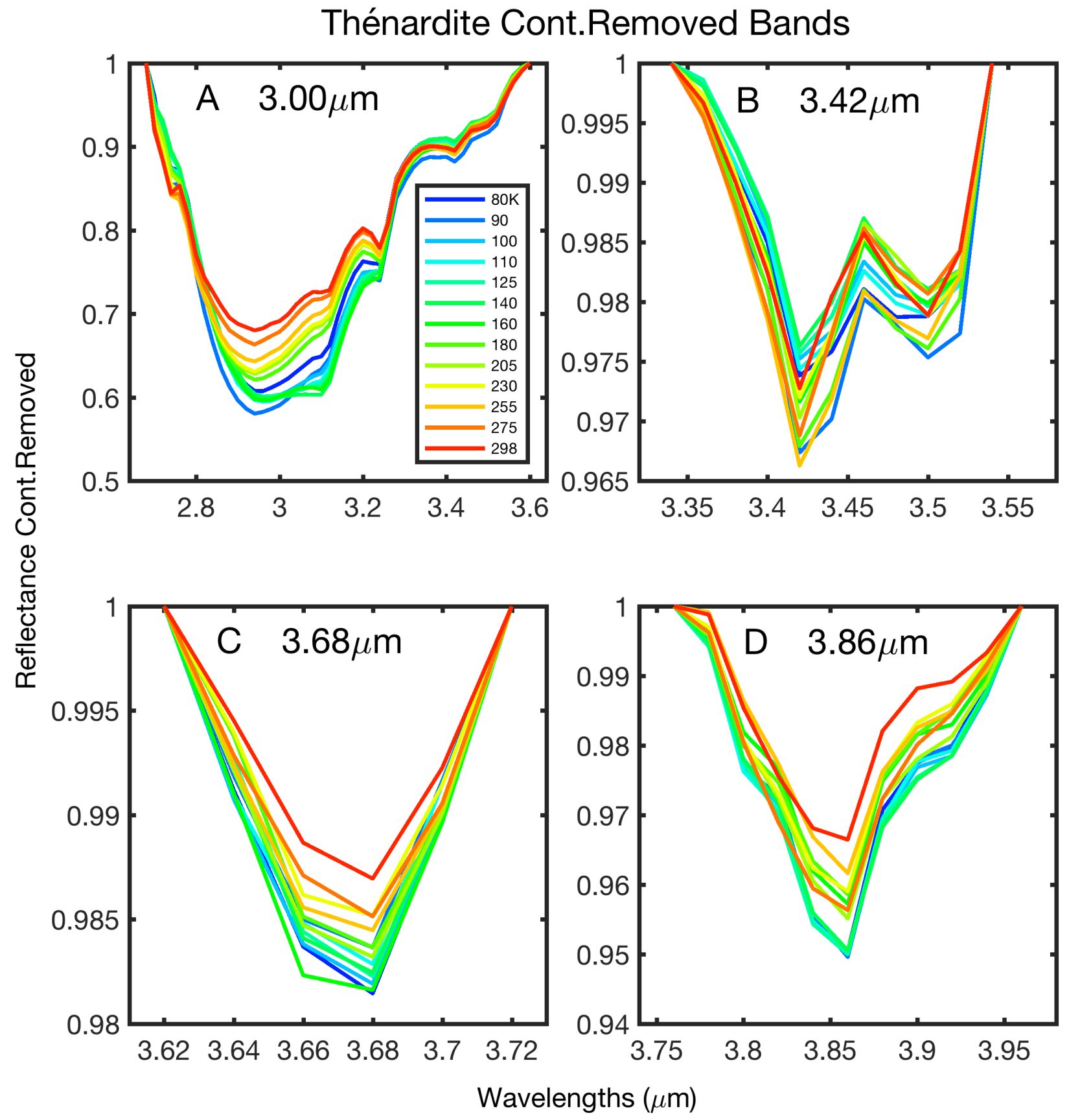

Fig. 4. Continuum removed bands for thénardite (anhydrous sodium sulfate), in the spectral range 3-4 $\mu \mathrm{m}$. The procedure for continuum removal is described in Section 2.3. Here we show only the spectra for the "fine" grain size $(36-50 \mu \mathrm{m})$. 


\section{Thénardite $4.60 \mu \mathrm{m}$ Cont.Removed Band}
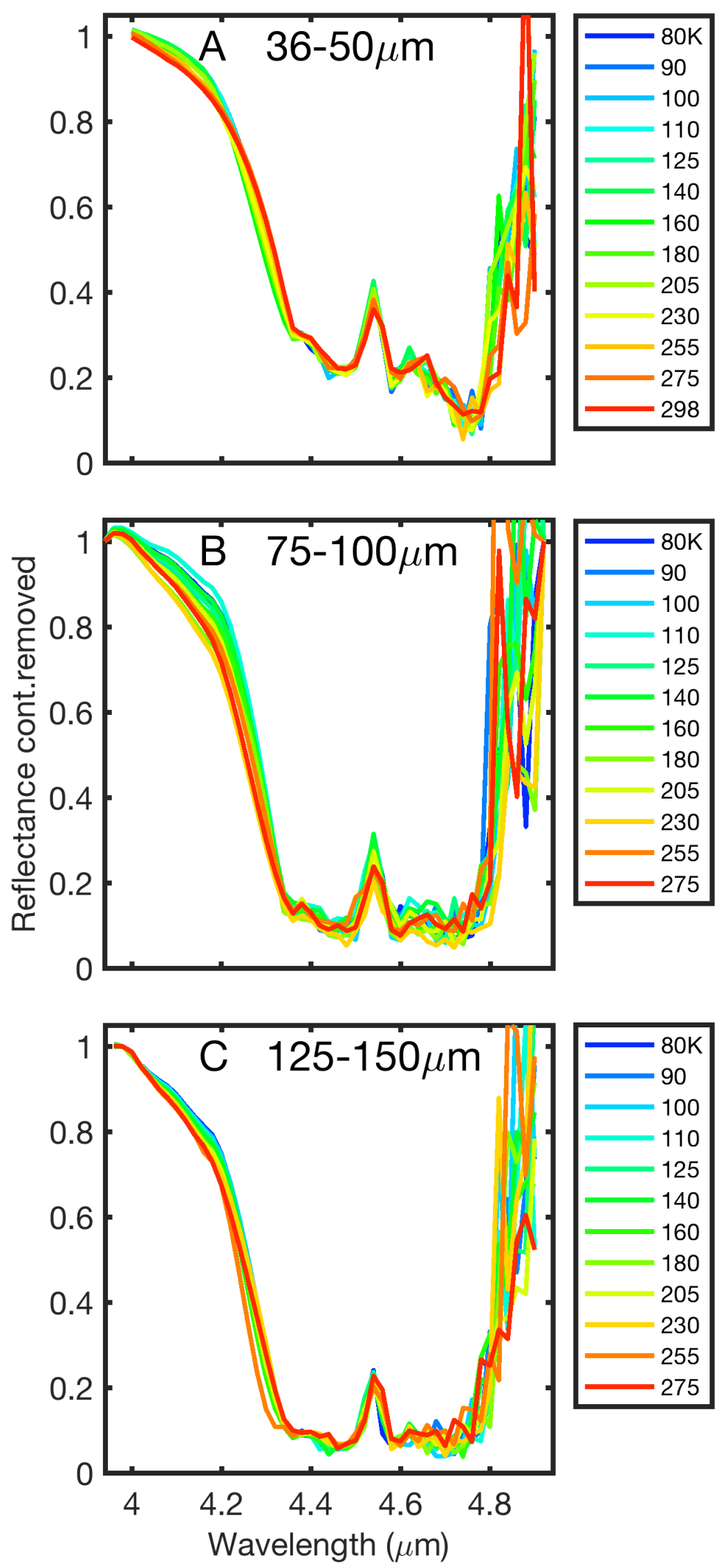

Fig. 5. Continuum removed 4.6-um band doublet for thénardite (anhydrous sodium sulfate). The procedure for continuum removal is described in Section 2.3. We compare the shape of the band for all three grain sizes. 
Thénardite 3- $\mu \mathrm{m}$-complex band parameters
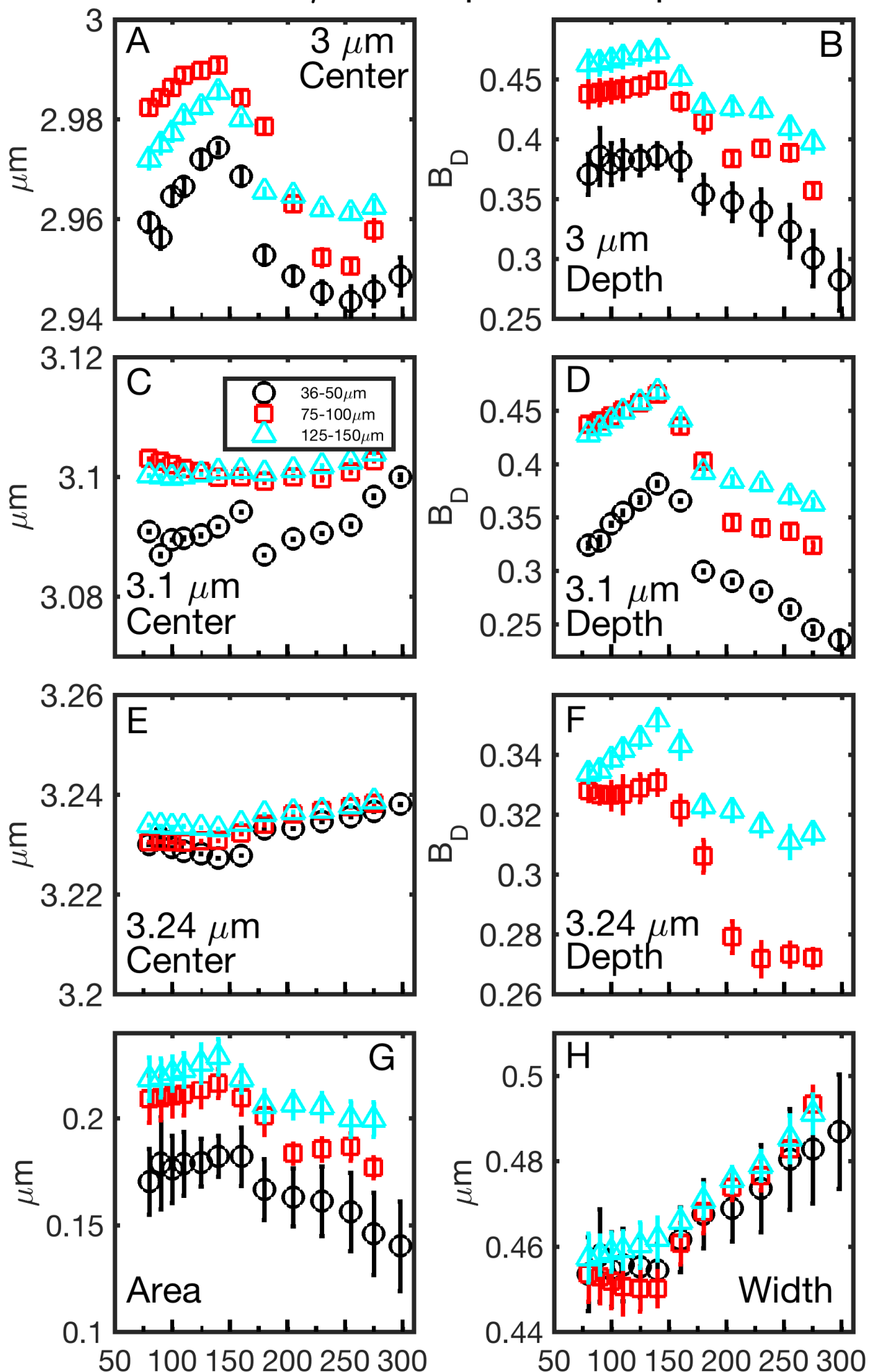

Temperatures $(\mathrm{K})$

Fig. 6. Anhydrous sodium sulfate (thénardite): 3- $\mu$ m band spectral parameters, as a function of temperature. The four panels respectively report the trend of: band center, band depth, band area and band width. The method used to compute these parameters is described in Section 2.3. In each panel the symbols indicate the different grain sizes: circle for the "fine" grain size (36-50 $\mu \mathrm{m})$, square for the "intermediate" grain size (75-100 $\mu \mathrm{m})$, and triangle for the "coarse" grain size (125$150 \mu \mathrm{m})$. 


\subsubsection{Sodium sulfate decahydrate}

The continuum removed absorption features of sodium sulfate decahydrate, or mirabilite, are displayed in Fig. 7. Some of them tend to exhibit a fine structure at the lowest temperatures. Band parameters as a function of temperature are shown in Fig. 8-9 (and fig.2A in the Online Supplementary Material), for selected features of interest.

\section{2- $\mu \mathrm{m}$ band}

Band parameters are shown in Fig. 8 (left panels). This feature, which is related to $\mathrm{H}_{2} \mathrm{O}$ in the mineral structure proves to be strongly temperature-dependent in the considered range. The band position moves from about $1.21 \mu \mathrm{m}$ at room temperature $(300 \mathrm{~K})$ to 1.22 $\mu \mathrm{m}$ at the lowest temperature, with a total shift of about $11 \mathrm{~nm}$. Depth and area increase quite linearly as the temperature drops down, by roughly $20 \%$. The band width decreases monotonically with decreasing temperature, by more than $10 \%$. The effect of grain size is very evident for all the four parameters. At a given temperature, the band center moves towards shorter wavelengths as the grain size becomes larger. Concerning the other parameters (depth, area and width), their value at a given temperature are greater for larger grain sizes.

\section{$1.46-\mu m$ band}

Parameters are displayed in Fig. 8 (right panels). Also in this case the band center is notably temperature dependent, with a shift of about $6 \mathrm{~nm}$ towards longer wavelength with decreasing cryogenic temperature. Band depth and area increase monotonically with decreasing temperature, by a factor of about $10 \%$ and $14 \%$ respectively. The FWHM is characterized by a nonlinear behavior, increasing up to a maximum, at $T=120 \div 180 \mathrm{~K}$ depending on grain size, and then decreasing as the temperature decreases. This behavior could be a combined effect of the shift in position and the appearance of a shoulder around $1.55 \mu \mathrm{m}$ on the high wavelength side of the band at the lowest temperatures (Fig. 7). Here the effect of grain size is clearer on depth, area and width parameters, for which the fine $(36-50 \mu \mathrm{m})$ assumes values substantially lower than the other grain sizes.

\subsection{8- $\mu \mathrm{m}$ band}

The spectral parameters of this feature (Fig. 9, left panels) are characterized by a somehow different behavior with respect to the previous two bands. The band position moves to shorter wavelengths by 3-7 nm as the temperature decreases. Band depth, area and width all increase with decreasing temperature, by a factor of $36 \%, 40 \%$ and $14 \%$, respectively. But below $100 \mathrm{~K}$, the trend reverse for the smallest grain size, only, with depth and area slightly decreasing . In general, band depth and area assume higher values for the larger grain sizes. The shift in position for a given temperature is not linear with grain size.

\section{0- $\mu \mathrm{m}$ band}

The behavior of this band with temperature is very similar to that of $1.46-\mu \mathrm{m}$ feature (Fig. 8). The band center shifts by less than $10 \mathrm{~nm}$ towards longer wavelengths as the temperature decreases, in the range 1.96-1.97 $\mu \mathrm{m}$. The shift in position is also grain size dependent, with the smaller grains $(36-50 \mu \mathrm{m})$ positioned at shorter wavelengths, and the 
medium grains $(75-100 \mu \mathrm{m})$ positioned at longer wavelengths. Depth and area slightly increase with decreasing temperature. Maximum values are assumed by the intermediate grain size, while minimum values by the fine grain size. Bandwidth increases monotonically with temperature decreasing, except for the fine grain size, for which it is maximum at $100 \mathrm{~K}$.

\subsection{7- $\mu \mathrm{m}$ band}

The spectral parameters for this feature are displayed in Fig. 9 (right panels). The band position does not appear to be significantly dependent on temperature: the measured shift is about 2-3 nm, which is well below the spectral sampling used for our measurements. Depth, area and width increase quite monotonically with temperature reduction, by a factor of $17 \%, 40 \%$ and $12 \%$ respectively. Depth and area assume maximum values for the intermediate grain size $(75-100 \mu \mathrm{m})$ and minimum values for the fine grain size (36-50 $\mu \mathrm{m})$. The bandwidth assumes increasing values linearly with increasing grain size. The behavior of depth, area and width as a function of temperature reduction is quite monotonic for the 75-100 $\mu \mathrm{m}$-grain size; such parameters assume a narrow maximum peak at $100 \mathrm{~K}$ for the $36-50 \mu \mathrm{m}$-grain size, then start to decrease; the maximum region is broad, a plateau extending for $\mathrm{T}<150 \mathrm{~K}$, for the (larger) 125-150 $\mu \mathrm{m}$-grain size.

\section{0- $\mu \mathrm{m}$ band}

The continuum-removed band is shown in Fig. 7, and relative spectral parameters are displayed in Fig. 2A (Online Supplementary Material; left panels) against temperature. The position appears to be very sensitive to temperature change, and in a non-linear manner, although the band bottom is very broad and nearly flat. As the temperature decreases, the position shifts by more than $50 \mathrm{~nm}$ towards longer wavelengths; the shift becomes more than $100 \mathrm{~nm}$ for the 125-150- $\mu \mathrm{m}$ grain size (2.93-3.10 $\mu \mathrm{m})$. At $T=150 \mathrm{~K}$ the position starts to shift back towards shorter wavelengths. This behavior could be ascribed to the beginning of separation of the two distinct water stretching modes, at 2.9 and $3.1 \mu \mathrm{m}$ at this temperature. At a given temperature, the band position is shifted towards shorter wavelengths for the 36-50 $\mu \mathrm{m}$-grain size, and towards longer wavelengths for the 75-100 $\mu \mathrm{m}$-grain size. The depth has also a non-linear behavior, increasing up to a maximum at $150 \mathrm{~K}$ and then decreasing, with temperature reduction. The band area shows a nearly monotonic decrease with temperature reduction, especially for the 36-50, but starting to display a sharp increase around $150 \mathrm{~K}$ for larger grain sizes. Bandwidth shows a strong narrowing as the temperature decreases, by a factor of $20 \%$.

\section{8- $\mu \mathrm{m}$ band}

The spectral parameters are shown in Fig. 2A (online supplementary material; right panels). This feature is weak and only shows up at temperature values below 180K; it proves to be significantly temperature-sensitive. The position shifts by about 15-30 nm towards shorter wavelengths as the temperature decreases (3.80-3.77 $\mu \mathrm{m})$. Depth and area increase monotonically as the temperature decreases, by a factor of 5-10 depending on the grain size (fine or intermediate, respectively). The bandwidth increases with temperature drop off, reaching a maximum around $100 \mathrm{~K}$. 


\section{6- um band}

The strongest sulfate band in the explored spectral range, centered at about $4.6 \mu \mathrm{m}$, is displayed in Fig. 7. Because the upper limit of sensitivity of the SHINE facility is $5 \mu \mathrm{m}$, and the signal-to-noise is very low beyond $4.6 \mu \mathrm{m}$, it was impossible to properly measure the right shoulder of the band, making it hard to safely derive spectral parameters. Here we can qualitatively state that this feature appears substantially different in the decahydrate form with respect to the anhydrous form (compare Fig. 4 with Fig. 7). In mirabilite, this band is shifted towards longer wavelengths, with a unique minimum near $4.8 \mu \mathrm{m}$. The short wavelength edge is less steep than in the case of thénardite. In thénardite the band displays two minima at 4.45 and $4.60 \mu \mathrm{m}$, separated by an interband peak (minimum of absorption) at $4.53 \mu \mathrm{m}$. This peak does not appear in spectra of mirabilite. 


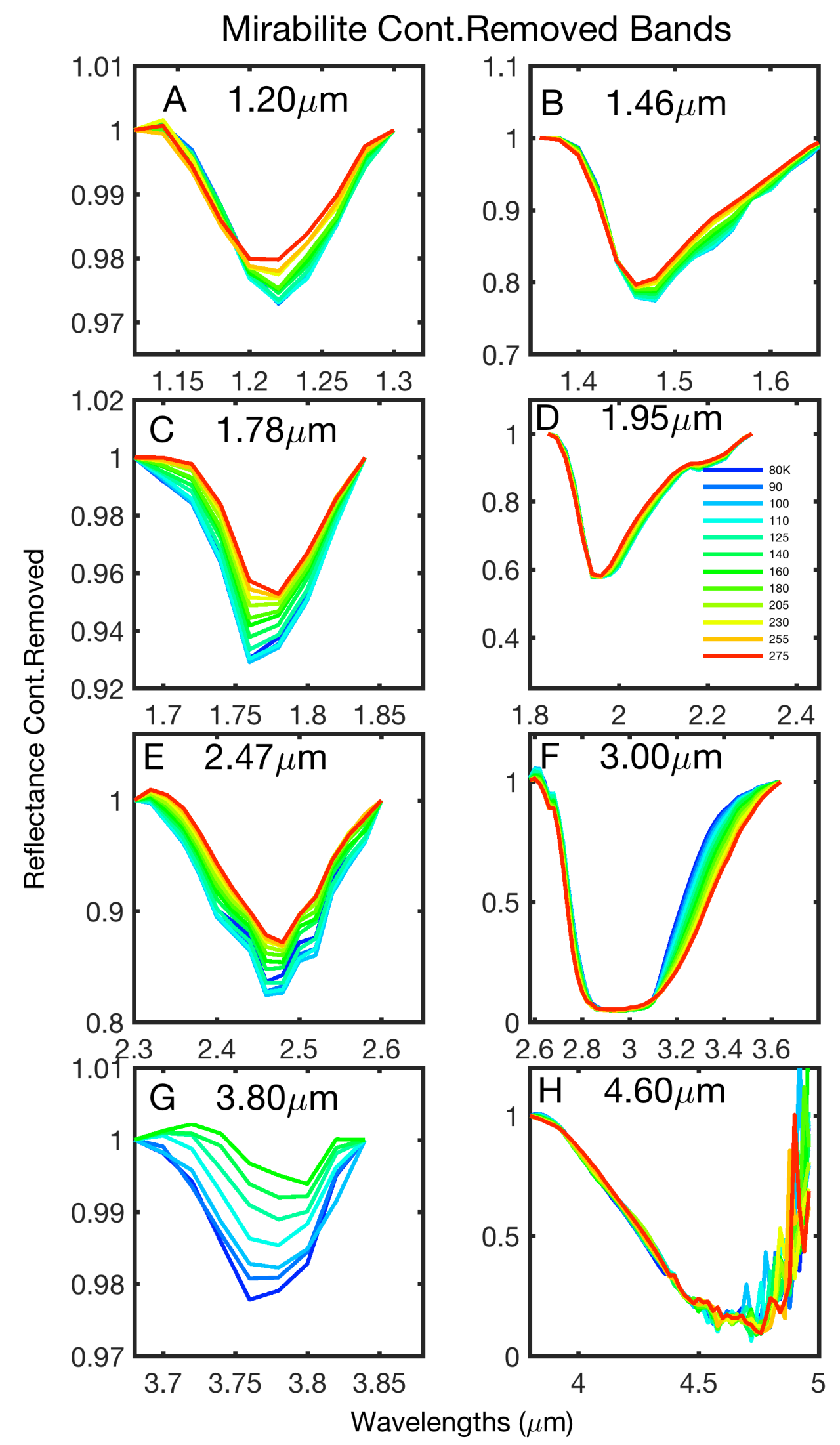

Fig. 7. Continuum-removed bands for mirabilite (sodium sulfate decahydrate). The method used to compute these parameters is described in Section 2.3. Here we show the fine grain size (36-50 um) spectra. 


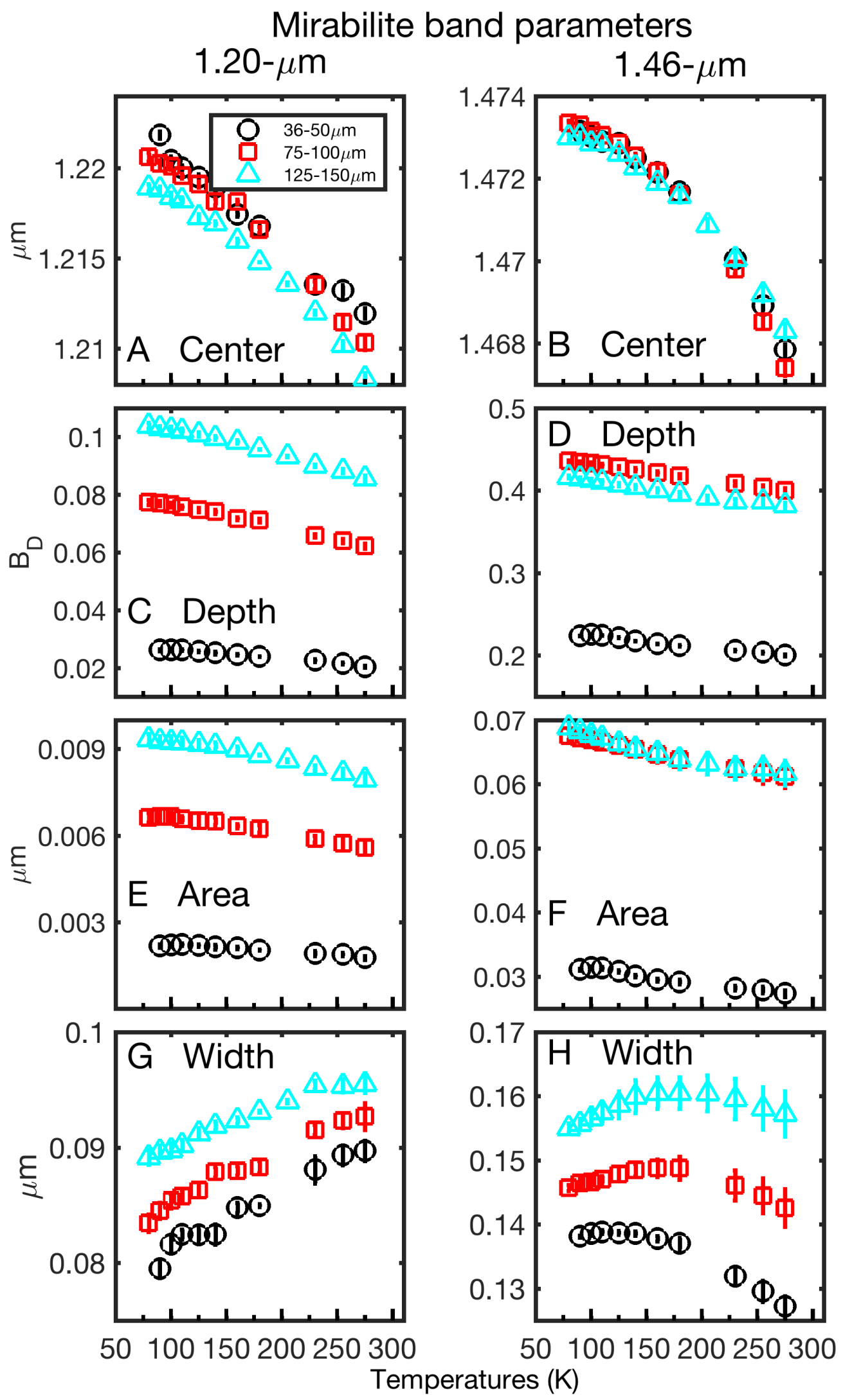

Fig. 8. Sodium sulfate decahydrate (mirabilite): 1.20 and 1.46- $\mu \mathrm{m}$ band spectral parameters as a function of temperature. We report the parameters: band center, band depth, band area, and band width. The method used to compute these parameters is described in Section 2.3. In each panel the symbols indicate the different grain sizes: circle for the "fine" grain size (36-50 $\mu \mathrm{m})$, square for the "intermediate" grain size (75-100 $\mu \mathrm{m})$, and triangle for the "coarse" grain size (125-150 $\mu \mathrm{m})$. 


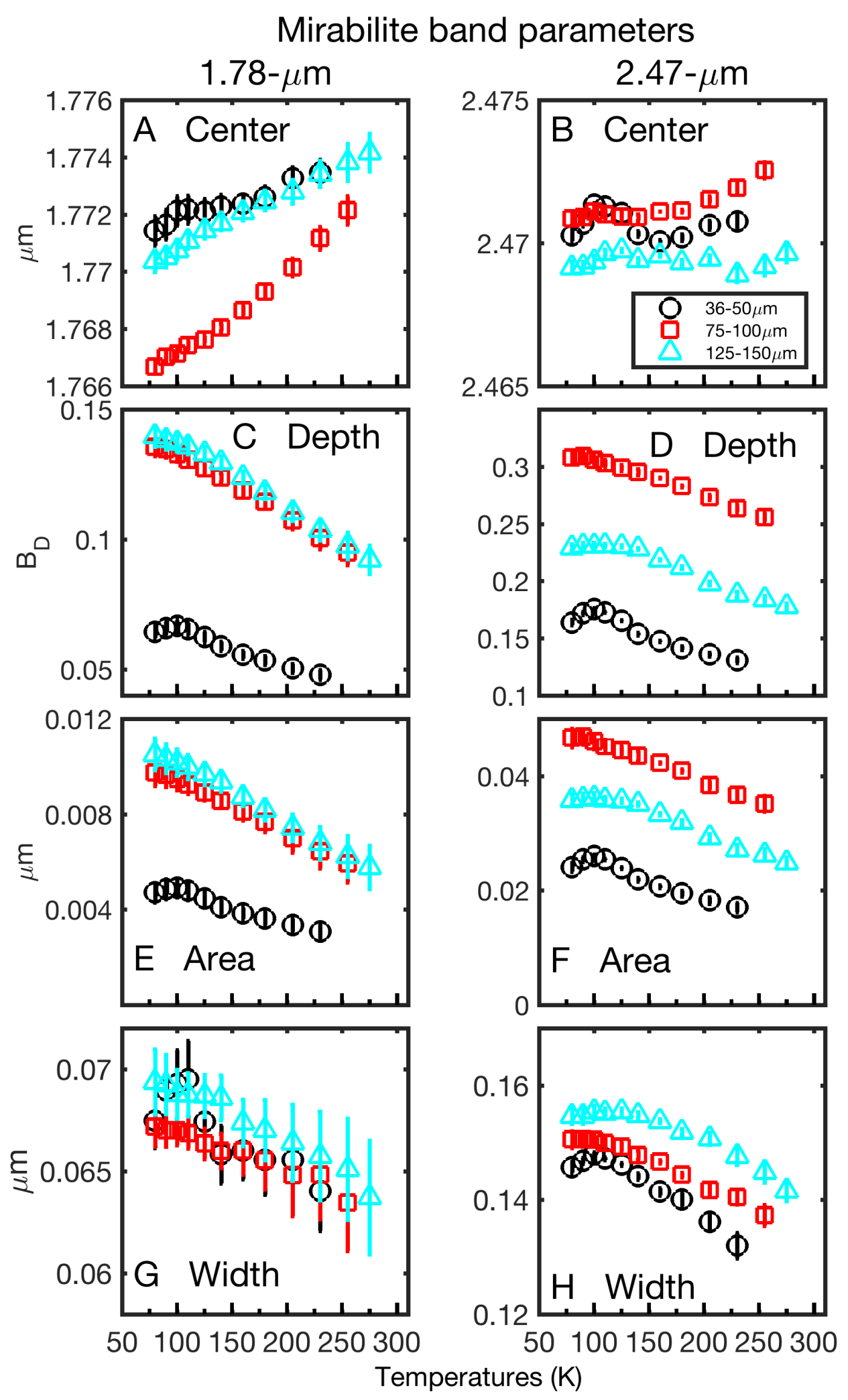

Fig. 9. Sodium sulfate decahydrate (mirabilite): 1.78 and 2.47- 4 m band spectral parameters, as a function of temperature. We display the spectral parameters: band center, band depth, band area, and band width. The method used to compute these parameters is described in Section 2.3. In each panel the symbols indicate the different grain sizes: circle for the "fine" grain size (36-50 $\mu \mathrm{m})$, square for the "intermediate" grain size (75-100 $\mu \mathrm{m})$, and triangle for the "coarse" grain size (125$150 \mu \mathrm{m})$. 


\section{Discussion}

\section{Effect of temperature on bands}

In the thénardite spectra the 3- $\mu \mathrm{m}$ band complex is related to small quantities of ambient adsorbed water. This feature is very sensitive to temperature variation, although band parameters do not show a monotone trend. Minima at 2.9, 3.1 and 3.24 $\mu \mathrm{m}$ all increase in intensity (band depth) as the temperature drops down, reaching a maximum depth near $150-160 \mathrm{~K}$, then start to decrease as the temperature decreases to $80 \mathrm{~K}$. The increase in intensity is higher for the 3.1- $\mu \mathrm{m}$ feature than the other two features. At ambient temperature and at $80 \mathrm{~K}$ the minimum (after continuum removal) of the band complex occur near $2.9 \mu \mathrm{m}$, while at the intermediate temperature $150 \mathrm{~K}$ the minimum seems to be $3.1 \mu \mathrm{m}$ (fig.4). A similar behavior occurs for the 3- $\mu \mathrm{m}$ complex in mirabilite (fig.2A), for which the $3.1-\mu \mathrm{m}$ secondary minimum increases to its maximum intensity as the temperature drops down to $150 \mathrm{~K}$, then starts to decrease. This seems to indicate that a certain process is occurring in both samples, that causes the 3.1- $\mu \mathrm{m}$ feature to assume its maximum depth at about 150-160K. Taking into account that our spectra were taken during the heating phase $(80 \rightarrow 298 K)$, an explanation could be given by water ice desorption, which occurs at $160 \mathrm{~K}$, as observed in McCord et al., 2001 after heating mirabilite from 100 to $375 \mathrm{~K}$ during temperature-programmed-desorption experiments.

All other water-related bands in mirabilite $(1.20,1.46$ and $1.96 \mu \mathrm{m})$ show the same behavior with temperatures, shifting towards longer wavelengths as the temperature decreases. This is consistent with studies on IR spectroscopy of water ice (Grundy and Schmitt, 1998): the longward shift is due to an increase in hydrogen bond strength at lower temperatures. Bands at 1.78, 2.47 and $3.8 \mu \mathrm{m}$ in mirabilite shift towards shorter wavelengths as the temperature decreases, that is in an opposite direction with respect to water-related bands, and they are likely due to vibrations in the sulfate ion.

\section{8 vs $3.86 \mu \mathrm{m}$ band}

The 3.8- $\mu \mathrm{m}$ band in mirabilite, that could be attributed to sulfate, should correspond to a feature occurring in the anhydrous sample thénardite at $3.86 \mu \mathrm{m}$. The shift in position in mirabilite could be due to the presence of water, as reported also in Cloutis et al. (2006) in their study on a large number of sulfates. This shift is related to the influence of additional $\mathrm{H}_{2} \mathrm{O}$ molecules in the mineral structure, which modify the $\mathrm{S}-\mathrm{O}$ bond length.

\section{4-5- $\mu m$ sulfate complex band}

The intense and broad absorption band appearing in the 4-5 $\mu \mathrm{m}$ region, due to first order overtone and combinations of the fundamental $\mathrm{SO}_{4}{ }^{2-} v_{3}$ vibration at 8-10 $\mu \mathrm{m}$ (Cloutis et al. 2006), is the most characteristic and diagnostic feature of the sulfate minerals family in the Visible-Near-Infrared region below $5 \mu \mathrm{m}$. It can have different spectral shapes for different sulfates (Omori and Kerr, 1963; Cloutis et al. 2006). In particular this feature is notably different in thénardite and mirabilite. In the anhydrous sample (fig.5) the band extends between 4-4.9 $\mu \mathrm{m}$, and is characterized by an interband peak in reflectance centered near $4.53 \mu \mathrm{m}$. The peak height appears to increase in reflectance $(0.2-0.4)$ as the temperature decrease in the range $275-80 \mathrm{~K}$, at least for the $75-100-\mu \mathrm{m}$ grain size, due to the narrowing of both components. In mirabilite (fig.7) the band extends in the range 3.8-5.0 $\mu \mathrm{m}$ and is more asymmetric with the minimum positioned around $4.8 \mu \mathrm{m}$, although because of noisy data around $5 \mu \mathrm{m}$ it an accurate determination of position was not possible. The main 
difference is the absence, in mirabilite, of the interband peak at $4.53 \mu \mathrm{m}$. An explanation for this difference could be the presence of many $\mathrm{H}_{2} \mathrm{O}$ molecules influencing $\mathrm{S}-\mathrm{O}$ bonding in mirabilite, implying a broad range of vibration energies. Indeed in Cloutis et al. (2006) $\mathrm{H}_{2} \mathrm{O}$-bearing sulfates show broad absorptions in this range, while anhydrous or $\mathrm{OH}-$ bearing sulfates (barite, anglesite, anhydrite) have bands with many well-resolved minima.

\section{Effect of grain size}

The grain size influences a number of absorption bands and spectral parameters. Differences between spectra among the grain sizes are visible in fig.3. In thénardite 3.0, 3.68 and $3.86 \mu \mathrm{m}$ bands, band depth and area increase for larger grain sizes at a given temperature. Moreover the $3.0-\mu \mathrm{m}$ band is shifted at longer wavelengths $(2.99 \mu \mathrm{m})$ for the medium grain size, while it is shifted at shorter wavelengths $(2.97 \mu \mathrm{m})$ for the smallest grain size. Regarding the band in the 4-5 $\mu \mathrm{m}$ region in thénardite, the spectral shape changes gradually (fig.4): with increasing grain size the reflection peak shifts towards longer wavelengths, from roughly $4.50 \mu \mathrm{m}$ (g.s. 36-50 $\mu \mathrm{m})$ to $4.52 \mu \mathrm{m}$ (g.s. $75-100 \mu \mathrm{m})$ to $4.54 \mu \mathrm{m}$ (g.s. 125-150 $\mu \mathrm{m}$ ). Moreover, the bottom of the band, on the left and right of the interband peak, is characterized by a negative slope in the grain size $36-50 \mu \mathrm{m}$. As the grain size becomes larger, the slope decreases and the band becomes flatter, due to saturation.

In mirabilite, the band depth (for a given temperature) increases monotonously with grain size for the 1.20 and $1.78 \mu \mathrm{m}$ band, being minimum for the smaller grains and maximum for the largest grain size. For the bands at 1.46 and $2.47 \mu \mathrm{m}$ the band depth assumes the maximum value for the intermediate grain size. The 3- $\mu \mathrm{m}$ band complex shows the maximum depth for the smallest grain size. This can be explained by taking into account that weak absorption bands (i.e. 1.20 and $1.78 \mu \mathrm{m}$ ) tend to saturate at greater grain sizes than stronger bands (i.e. 1.46, 2.47 and $3.0 \mu \mathrm{m}$ ): that is the grain size of optimal band depth reduces as the absorption gets stronger (Hapke, 1993; Harloff \& Arnold, 2001).

\section{Extended-Visible parameters vs Temperature}

The Visible region of mirabilite spectra has also been studied; spectra in the Visible range are displayed in fig. 10 without any additional offset along Y-axis. Parameters such as slope, reflectance factor and area are shown in fig. 11 as functions of temperature. All parameters show changes with grain size and temperature. Two different slopes have been retrieved and compared with temperature and other spectral parameters: the visslope-1 $(0.40-0.54 \mu \mathrm{m})$ and vis-slope-2 (0.60-0.92 $\mu \mathrm{m})$. The slope-1 is generally positive (red) and reaches a positive maximum value. The slope-2 is negative (blue) and reaches a minimum (maximum absolute value).

The slope- 1 is only shown for the $75-100$ and $125-150 \mu \mathrm{m}$ grain size (fig.11A), because in the fine grain size it does not change appreciably. The change with temperature is characterized by a maximum value at about $150-160 \mathrm{~K}$. The slope-2 (fig.11B) has a behavior that is similar for the three grain sizes, reaching one or two minima (negative) in the $100-180 \mathrm{~K}$ range. The slope- 1 appears to be positively correlated with the $3-\mu \mathrm{m}$ band of water (fig.11C).

The reflectance at $0.6 \mu \mathrm{m}$ has been determined, as well as the maximum reflectance value in the 0.4-0.9- $\mu \mathrm{m}$ range and its wavelength position. The value of maximum reflectance is shown in fig.11D as a function of temperature. For all the grain sizes, as temperature drops down the reflectance increases, reaching a maximum near 150-160K. The reflectance is minimum for the lowest and highest temperatures. The wavelength position 
versus temperature of this reflectance peak is displayed in fig.11E: except for the room temperature value, the peak has its maximum shift towards longer wavelengths at 140$160 \mathrm{~K}$. Finally, for each temperature and grain size, the area comprised between the spectral data and a line joining the wavelengths 0.4-0.7 $\mu \mathrm{m}$ has been computed: this is a measure of the curvature of spectra in the VIS region. This parameter again appears to be maximum at $160 \mathrm{~K}$ and minimum at the lowest and highest temperatures.

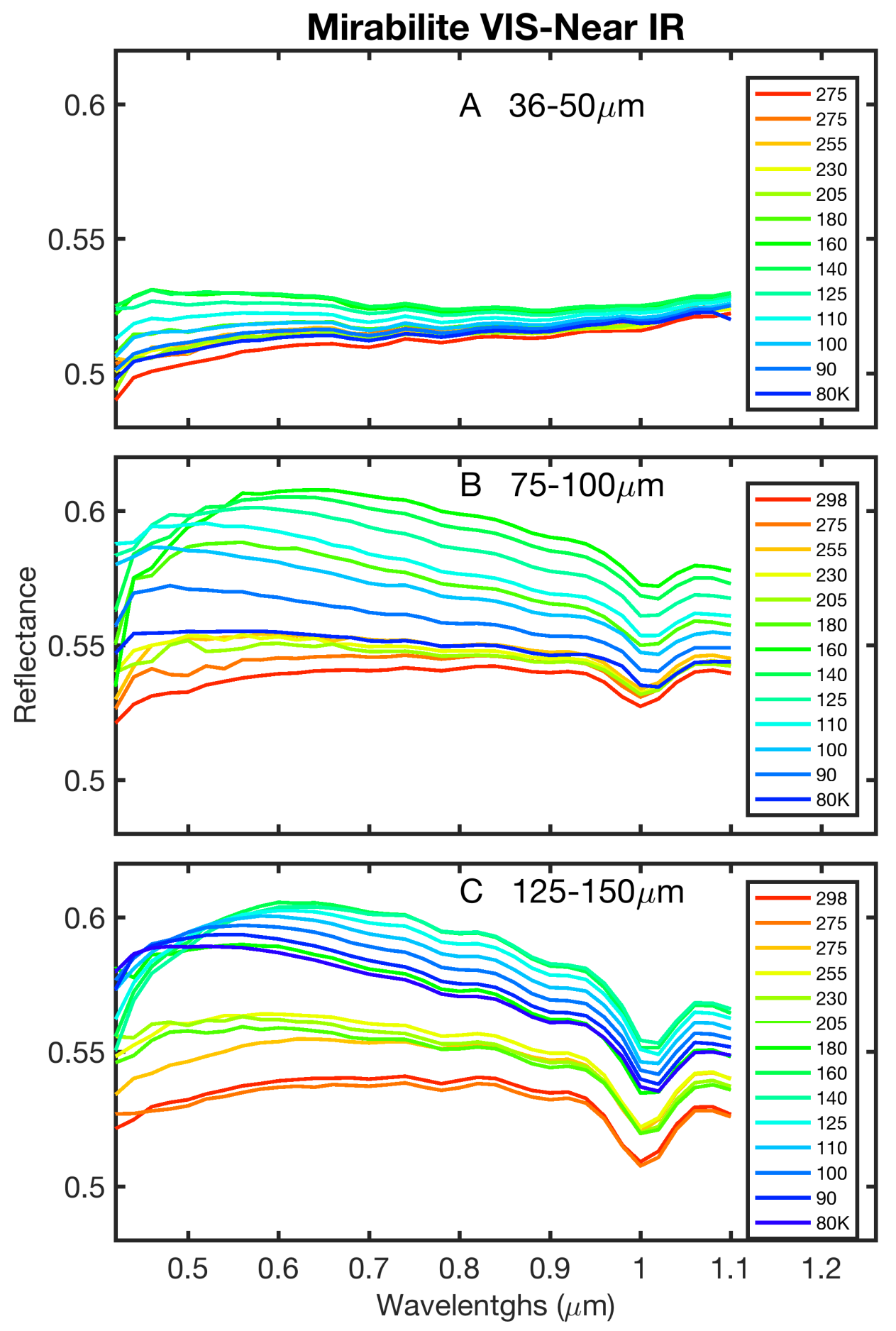

Fig.10. Mirabilite. Visible Near-IR spectra (0.4-1.1 $\mu \mathrm{m})$. 

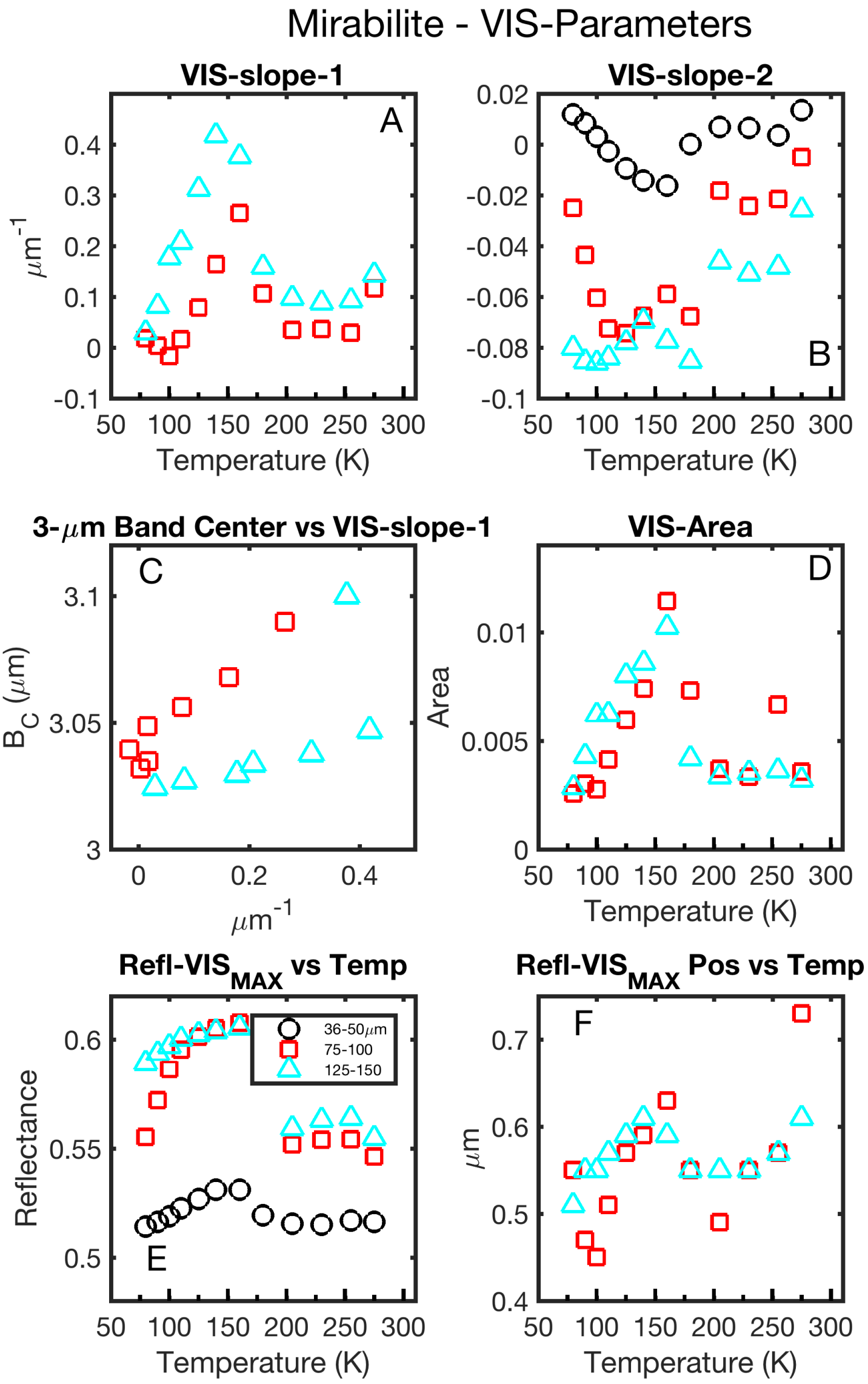

Fig.11. Mirabilite Visible parameters: slopes, reflectance, area. The retrieved parameters are described in the section above. 
Among non-water-ice compounds thought to exist on the surfaces of the icy Jovian satellites, hydrated salt minerals were first proposed to exist as a by-product of endogenic processes (McCord et al., 1998a, 1998b, 1999, 2002). While the agreement with nearinfrared spectral observations of dark terrains on Europa is indeed better for highly hydrated salts than for salts of lower hydration states, none of these materials alone can account for all of the observed spectral character (Dalton et al., 2005). Europa and Ganymede's non-ice material appears to be a complex mixture of sulfate hydrates and other materials (McCord et al., 1999). Best fits for non-icy terrains were initially found to be provided by mixtures of hydrated sodium sulfates, hydrated magnesium sulfates, which are typical endogenous products, and sulfuric acid hydrate, which instead is a product of radiolysis (Carlson et al., 1999; Dalton, 2007; Shirley et al., 2010).

In recent times, the traditional hypothesis of the presence of sulfate salts on the surface of Europa has been challenged as Mg-bearing chlorinated species (chloride, chlorate, and perchlorate) have been found to provide improved spectral fits in the NIR range (Ligier et al., 2016). Even more recently, on the basis of HST observations obtained in the visible range, sodium chloride $(\mathrm{NaCl})$ was suggested to be the main spectral endmember on the surface of Europa, implying a NaCl-rich ocean (Trumbo et al., 2019).

Despite these apparently diverging results, as a matter of fact the current chemical composition of the surfaces of Europa and Ganymede is expected to reflect, as far as the endogenous component is concerned, the composition of the subsurface ocean lying in the interiors of these moons. At least in the case of Europa, various salt minerals may form from direct contact of liquid water with a silicate mantle found on the ocean's floor. In this scenario, it is plausible to argue that several soluble salts might actually coexist within the ocean as well as on the surface, as a result of the transient water plumes that have been discovered over the last years (Roth et al., 2014; Sparks et al., 2016; Paganini et al., 2020). The different molecular weight of the salt minerals can then account for a potential stratified compositional sequence that is observed in the uppermost surface layer. In the case of Ganymede, no ongoing activity has been observed so far, and theoretical models of the interior seem to rule out a direct, constant and vigorous exchange between the internal liquid layer and a silicate mantle. Nonetheless, optical images show evidence for resurfacing and terrains with relatively recent geologic age, with grooves from which liquid water could have found its way out in the past. In compositional terms, this is in agreement with both NIR hyperspectral data returned by the NIMS spectrometer (McCord et al., 1998a), and with recent Earth-based observations (Ligier et al., 2019). These results ultimately suggest that Ganymede may have a surface composition close to that of Europa, with exogenous effects that are mitigated both by the larger distance from Jupiter and by the presence of an intrinsic magnetic field that protects the surface from high energy charged particles at low latitudes.

The primary scientific objective of the imaging spectrometers carried onboard the NASA Europa Clipper and ESA JUICE spacecrafts is to identify and map the composition of nonwater-ice materials on the surfaces of the icy Galilean satellites, with an emphasis on Europa and Ganymede, respectively. Separating endogenous and exogenic products, the latter being a constant byproduct of Jupiter's harsh radiation environment, is also a major objective. For this reason, it is essential to build a database of laboratory spectra measured in the same spectral range that will be covered by those instruments, and in a range of cryogenic temperature representative of those planetary surfaces. While our experiments do not take into account exogenic effects caused by radiation, the information deriving from the dependence of the spectral profiles on parameters such as temperature and grain size proves to be crucial in applying spectral unmixing models to the 
hyperspectral data sets that will be acquired, ultimately allowing both the identification of the most plausible chemical species and the estimation of their physical state.

Following this idea and using the same laboratory setup, in previous works we had already analyzed: 1) hydrated magnesium sulfates (De Angelis et al., 2017), and 2) hydrated and anhydrous sodium carbonates (De Angelis et al., 2019). In this regard, the present work represents the third set of mineral salts for which we took spectral profiles that may prove useful in view of future interpretation of data acquired by these spectrometers. Among the sodium sulfates considered here, the anhydrous form thénardite is very hygroscopic and requires a very dry environment to exist. Thus it is not expected on the surfaces of the icy satellites, which are dominated by water ice. Nevertheless the possibility exists that thénardite could be formed as secondary product after irradiation and dehydration of mirabilite, and persist for some time on the surface of Europa; such a mechanism, i.e. dehydration of salts into lower hydrated forms, has been shown to occur on Europa for Clbearing species (Thomas et al., 2017). It was chosen only as a reference compared to a stable hydrated form such as mirabilite, which instead is among the chemical species potentially expected to occur on the icy satellites. However, in mirabilite the spectral signatures are largely dominated by combinations and overtones of the water molecules that make up the mineral. Therefore, thénardite served above all to highlight the absorptions due to the $\mathrm{SO}_{4}{ }^{2-}$ ion and to facilitate our assignment of the observed spectral signatures in mirabilite.

The MAJIS spectrometer onboard the ESA JUICE mission covers the overall spectral range $0.50-5.54 \mu \mathrm{m}$, with an average spectral sampling step of $3.7 \mathrm{~nm} /$ band between 0.50 and of $2.35 \mu \mathrm{m}$ and $6.5 \mathrm{~nm} /$ band between 2.25 and $5.54 \mu \mathrm{m}$ (Piccioni et al., 2019). Consequently, the spectral sensitivity range is largely comparable to that of the SHINE facility that we used for this work, while the expected sampling step of MAJIS is better. On the other hand, the strong absorption of water ice on Europa and Ganymede results in very low reflectance beyond $2.7 \mu \mathrm{m}$, creating significant observational and signal-to-noise challenges in that region for infrared spectrometers. In this regard, the identification of the diagnostic features of mirabilite at 3.8 and $4.6 \mu \mathrm{m}$ could be more challenging than the identification of other diagnostic features located at at 1.78, $2.18 \mu \mathrm{m}$ and $2.47 \mu \mathrm{m}$, which, despite their variable strength (medium to very weak, see Table 1), are located in a spectral region favored by a larger signal coming from the target. On the other hand, a SNR > 30 should be large enough to reveal all these spectral signatures, especially those located beyond $2.7 \mu \mathrm{m}$, which could therefore guarantee a safe identification of the presence of pure deposits of mirabilite, if any, separating them from potential local exposures of other salt minerals.

The variation in the slope of the visible spectra of mirabilite as a function of temperature, which we observed in laboratory, is also preparatory for the interpretation of the spectra of the icy Galilean satellites that will be acquired by MAJIS in the visual range 0.5-1.0 $\mu \mathrm{m}$. Indeed, this highlights the need of including this spectral range to achieve a comprehensive evaluation of the surface composition, and it also emphasizes the science case of using multispectral images with JUICE in the visual range up to $1 \mu \mathrm{m}$ to highlight compositional variations potentially linked also to the presence of this mineral on the surface. The Mapping Imaging Spectrometer for Europa (MISE) instrument (Blaney et al., 2019) onboard NASA spacecraft Europa Clipper will observe the icy satellite in the 0.8-5 $\mu \mathrm{m}$ spectral range, with $10 \mathrm{~nm}$ spectral sampling and $25 \mathrm{~m} / \mathrm{px}$ at a distance of $100 \mathrm{~km}$. The MISE spectrometer has the capability to detect all the described spectral features relative to thénardite and mirabilite. Concerning thénardite absorption features at $3.1,3.24$, 3.68 and $3.86 \mu \mathrm{m}$, with FWHMs of about $30-50 \mathrm{~nm}$, could be easily detected. The detector cutoff at $5 \mu \mathrm{m}$ could allow observing the 4.6- $\mu \mathrm{m}$ sulfate band, although presumably with some noise in the long-wavelength edge. Regarding mirabilite all the absorption feature in 
this range have FWHMs well above the instrument resolution and are detectable. The fine structure arising at low temperatures in bands such as 1.46 and $2.47 \mu \mathrm{m}$ should also be resolved. The long-wavelength wing of 4.6- $\mu \mathrm{m}$ sulfate band could be detected but noisy. Mirabilite bands at 1.20 and $3.80 \mu \mathrm{m}$ display the largest shifts with temperature, being of the order of $>10 \mathrm{~nm}$ and $>20 \mathrm{~nm}$, towards longer and shorter wavelengths, respectively. Such shifts are potentially above the detection limit of both MAJIS and MISE instruments. At about $100 \mathrm{~K}$ these two bands are located near 1.22 and $3.77 \mu \mathrm{m}$. Using in conjunction band position and band depth, for example of the $3.80 \mu \mathrm{m}$ feature, the grain size can also be estimated. At $100 \mathrm{~K}$ this feature would have a band depth of about 0.02 for smaller grain sizes $(<50 \mu \mathrm{m})$, while it would be about 0.05 for larger grains $(>125 \mu \mathrm{m})$. Monitoring of changes in VIS slope over time can also be useful in order to detect temperature variations with time.

\section{Implication for Mars missions}

Missions planned to explore the Mars surface in the next future (NASA/Mars 2020 and ESA-RosCosmos/ExoMars 2022) host optical cameras and infrared spectrometers that are in principle capable to detect thénardite and mirabilite. Mastcam-Z on Mars 2020 Rover (Bell III et al., 2020) will observe the surface in the extended visible region up to 1 $\mu \mathrm{m}$, thus with the capability of detect water combination/overtone bands related to the presence of hydrated minerals and eventually also mirabilite (Rice et al., 2010). Ma_MISS spectrometer (De Sanctis et al., 2017) inside the drill of the ExoMars 2022 rover has the potentiality of detect hydrated minerals in the Mars subsurface if present. In particular the mirabilite bands at 1, 1.2, 1.46 and $1.78 \mu \mathrm{m}$ fall in the sensitivity range of this instrument. The ISEM spectrometer (Korablev et al., 2017) onboard ExoMars rover, with its 1.1-3.3 $\mu \mathrm{m}$ range, will have the capability of measure mirabilite hydration bands from the 1.2 to the 3$\mu \mathrm{m}$ band, although this last would be truncated, and the thénardite bands at 3.1-3.24 $\mu \mathrm{m}$.

\begin{tabular}{|c|c|c|c|c|c|c|c|c|c|}
\hline Sample & $B(\mu m)$ & $B_{C} v s T$ & $\Delta B_{C}$ & $B_{D} v s T$ & $\Delta B_{D}$ & $B_{A} v S T$ & $\Delta B_{A}$ & $B_{w} v s T$ & $\Delta B_{w}$ \\
\hline \multirow[t]{7}{*}{$\mathrm{Na}_{2} \mathrm{SO}_{4}$} & $2.9-3.0$ & $\begin{array}{l}\vec{\rightarrow}(300-160 \mathrm{~K}) \\
\leftarrow(160-80 \mathrm{~K})\end{array}$ & $\begin{array}{l}+40 \\
-20 \\
\end{array}$ & $\uparrow$ & $40 \%$ & $\uparrow$ & $20 \%$ & $\downarrow$ & $10 \%$ \\
\hline & 3.1 & - & $<<5$ & $\downarrow$ & $40 \%$ & $\uparrow$ & $20 \%$ & $\downarrow$ & $10 \%$ \\
\hline & 3.24 & 4 & $<10$ & $\uparrow$ & $25 \%$ & $\uparrow$ & $30 \%$ & $\downarrow$ & $10 \%$ \\
\hline & $3.42(\mathrm{I})-3.5(\mathrm{II})$ & - & $<<5$ & $\uparrow$ & $10 \%$ & $\uparrow$ & $30 \%$ & $\downarrow$ & $10 \%$ \\
\hline & 3.68 & - & $<<5$ & $\uparrow$ & $15 \%$ & $\uparrow$ & $20 \%$ & - & \\
\hline & 3.86 & - & $<<5$ & $\uparrow$ & $20 \%$ & $\uparrow$ & $20 \%$ & - & \\
\hline & $4.0-4.9$ & - & & - & & - & & - & \\
\hline \multirow[t]{8}{*}{$\mathrm{Na}_{2} \mathrm{SO}_{4} \cdot 10 \mathrm{H}_{2} \mathrm{O}$} & 1.2 & $\Rightarrow$ & +12 & $\uparrow$ & $20 \%$ & $\uparrow$ & $15 \%$ & $\downarrow$ & $10 \%$ \\
\hline & 1.46 & $\rightarrow$ & +7 & $\uparrow$ & $10 \%$ & $\uparrow$ & $15 \%$ & $\uparrow$ & $10 \%$ \\
\hline & 1.78 & $\leftarrow$ & -8 & $\uparrow$ & $35 \%$ & $\uparrow$ & $40 \%$ & $\uparrow$ & $10 \%$ \\
\hline & 1.95 & $\rightarrow$ & +8 & $\uparrow$ & $5 \%$ & $\uparrow$ & $10 \%$ & $\uparrow$ & $10 \%$ \\
\hline & 2.47 & 4 & -4 & $\uparrow$ & $15 \%$ & $\uparrow$ & $30 \%$ & $\uparrow$ & $15 \%$ \\
\hline & 3.0 & $\begin{array}{l}\rightarrow(300-160 \mathrm{~K}) \\
\leftarrow(160-80 \mathrm{~K})\end{array}$ & $>50$ & 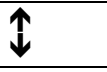 & $30 \%$ & $\downarrow$ & $20 \%$ & $\downarrow$ & $20 \%$ \\
\hline & 3.8 & $\leftarrow$ & -30 & $\uparrow$ & $50-90 \%$ & $\uparrow$ & $80 \%$ & $\uparrow$ & $40 \%$ \\
\hline & $4.0-4.9$ & - & & - & & - & & - & \\
\hline
\end{tabular}

Tab.2. Band parameters and their dependence on temperature for thénardite and mirabilite. Only the bands analyzed are shown. The vibration mode attribution of each band is listed in tab.1. $B_{C}$ vs T: Left arrow: shift towards shorter wavelengths; Right arrow: shift towards longer wavelengths. The shifts $(\Delta)$ are expressed in $\mathrm{nm}$ for band center; for depth, area and width as \% variation. The up/down changes in parameters ( $B_{D / A W} v s$ T columns) are for decreasing temperature. When both up and down arrows are present, they are relative to the temperature ranges 300-160K and 160$80 K$. 


\section{Conclusions}

Visible and near-infrared spectra of the anhydrous sodium sulfate (thénardite) and the decahydrated phase (mirabilite) are characterized by different patterns of absorption features, varying with temperature changes in different ways.

Thénardite has a flat and nearly featureless spectrum up to $2.6 \mu \mathrm{m}$. Apart from a 3- $\mu \mathrm{m}$ band due to adsorbed water, diagnostic sulfate bands occur at $3.68,3.86$ and especially at 4.6 $\mu \mathrm{m}$. Bands at 3.1 and $3.24 \mu \mathrm{m}$ could be also diagnostic of thénardite. A feature appearing at 3.42-3.5 $\mu \mathrm{m}$ can also be tentatively attribute to sulfate, although the position is also consistent with $\mathrm{C}-\mathrm{H}$ vibration. The 4.6- $\mu \mathrm{m}$ large doublet is characteristic of sulfates in the VIS-NIR region. In thénardite this strong band is characterized by an interband peak near $4.5 \mu \mathrm{m}$, separating two minima. The band shape does not seem to vary appreciably with temperature, although it gradually changes with grain size, becoming flatter and with decreasing slope (in absolute value) as the grain size increases.

Spectra of mirabilite are characterized by a large number of water related features, occurring near $1,1.2,1.46,1.78,1.95,2.47,3 \mu \mathrm{m}$, and by at least two features due to sulfate at 3.8 and $4.6 \mu \mathrm{m}$. The $1.78-\mu \mathrm{m}$ feature is reported also in other hydrated sulfates. In mirabilite the $\mathrm{SO}_{4}{ }^{2-}$ first overtone band occurring at $4.6 \mu \mathrm{m}$ is notably different from the anhydrous phase, being characterized by the absence of the interband peak near $4.5 \mu \mathrm{m}$, and with the minimum shifted towards longer wavelengths. Due to the high hydration state this band is much more broadened in mirabilite. Water-related features show generally shifts towards longer wavelengths as the temperature drops down, while 1.78, 2.47 and 3.8- $\mu \mathrm{m}$ bands slightly shifts in the opposite sense, i.e. towards shorter wavelengths.

The visible region up to $1.1 \mu \mathrm{m}$ in the spectra of mirabilite, being characterized by a spectral slope that correlates with temperature changes, is also of interest with the aim of interpreting remote sensing data from future missions such as JUICE and Europa Clipper. Although recently the general idea about the surface composition of Europa and Ganymede has changed, pointing to a greater complexity and variety in terms of mineral species present on these bodies, nevertheless our dataset is important in order to characterize also this type of compounds, given that mirabilite could be present as component in more complex mixtures.

\section{On-line data}

The complete sets of data (De Angelis et al., 2018a, 2018b) presented in this paper are available online upon publication of this paper in the REFL_SLAB and CSS databases of the SSHADE database infrastructure - (https://vwww.sshade.eu): https://doi.org/10.26302/SSHADE/EXPERIMENT_CC 20180427_001 and https://doi.org/10.26302/SSHADE/EXPERIMENT_CC_20180428_002.

\section{Acknowledgements}

The set of measurements described in this work is the outcome of the research project: "Characterization of Na-sulfates at Cold Planetary Conditions" (PI: Dr. Federico Tosi, Co-I Dr. Simone De Angelis), selected and funded in June 2017 in the framework of the European Union's Horizon 2020 Research Infrastructure (RI) programme (http://www.europlanet-2020-ri.eu), under grant agreement No. 654208. This work was partly supported by the Italian Space Agency (ASI), ASI-INAF grant 2013-056-R.O., and by the Centre National d'Etude Spatiale (CNES). We also wish to thank J.L.Bishop and an anonymous reviewer for their precious comments and suggestions. 


\section{References}

Babel M. and Schreiber B.C.: Geochemistry of Evaporites and Evolution of Seawater, Chapter, DOI: 10.1016/B978-0-08-095975-7.00718-X, In book: Treatise on Geochemistry, 2nd ed., v. 9. Sediments, Diagenesis, and Sedimentary Rocks, Chapter 9.17, Publisher: Elsevier, Editors: Mackenzie Fred, pp.483-560, 2014

Bell III J.F., J.N. Maki, G.L. Mehall, M.A. Ravine, M.A. Caplinger3 Z.J. Bailey, K.M. Kinch4, M.B. Madsen, B. Betts, E. Cisneros, B.L. Ehlmann, A. Hayes, B. Horgan, E. Jensen, J.R. Johnson, K. Paris, M. Rice, A. Winhold, M.J. Wolff, M. Barrington, E. Cloutis, N. Cluff, A. Coates, A. Colaprete, P. Corlies, K. Crawford, R. Deen, K. Edgett, S. Fagents, J. Grotzinger, C. Hardgrove, K. Herkenhoff, R. Jaumann, M. Lemmon, L. Mehall, G. Paar, M. Caballo-Perucha, F. Preusker, M.S. Robinson, C. Rojas, N. Schmitz, R. Sullivan, and C. Tate, 2020. The Mars 2020 Rover Mast Camera Zoom (Mastcam-Z) Multispectral, Stereoscopic Imaging Investigation, 51st Lunar and Planetary Science Conference, abs.1305, 2020

Bishop, J. L., Koeberl, C., Kralik, C., Froeschl, H., Englert, P. A. J., Andersen, D. W., Pieters, C. M., Wharton, R. A., 1996. Reflectance spectroscopy and geochemical analyses of Lake Hoare sediments, Antarctica. Geochimica Cosmochimica Acta. 60, 765-785.

Bishop, J. L., Pieters, C. M., Hiroi, T., Mustard, J. F., 1998. Spectroscopic analysis of martian meteorite Allan Hills 84001 powder and applications for spectral identification of minerals and other soil components on Mars. Meteoritics and Planetary Science. 33, 699708.

Bishop, J. L., Lougear, A., Newton, J., Doran, P. T., Froeschl, H., Trautwein, A. X., Körner, W., Koeberl C., 2001. Mineralogical and geochemical analyses of Antarctic sediments: A reflectance and Mössbauer spectroscopy study with applications for remote sensing on Mars. Geochimica Cosmochimica Acta. 65, 2875-2897.

Bishop J.L. and Murad E.: The visible and infrared spectral properties of jarosite and alunite, American Mineralogist, vol.90, pp.1100-1107, 2005

Bishop, J. L., Lane, M. D., Dyar, M. D., King, S. J., Brown, A. J., Swayze, G., 2014. Spectral properties of Ca-sulfates: Gypsum, bassanite and anhydrite. American Mineralogist. 99, 2105-2115

Bishop J.L., Flahaut, J., Martinot, M., Potts, N.J., Davies, G.: Combined VNIR and Raman spectroscopy of the Atacama salt flats as a potential Mars analog, American Geophysical Union, Fall Meeting, abstract id.P31A-2040, 2015

Blaney D.L., Hibbitts C., Green R.O., Clark R.N., Dalton J.B., Davies A.G., Langevin Y., Lunine J.I., Hedman M., McCord T.B., Murchie S.L., Paranicas C., Seelos IV F.P., Soderblom J.M., Diniega S., Cable M., Thompson D., Bruce C., Santo A., Redick R., Hahn D., Bender H., Van Gorp B., Rodriguez J., Sullivan P., Neville T., Lundeen S., Bowers M., Ryan K., Hayes J., Bryce B., Hourani R., Zarate E., Moore L.B., Maynard K., McKinley I.M., Johnson D., Aubuchon P., Fedosi J., Wehbe R., Calvet R., Mouroulis P., White V., Wilson D., 2019: The Europa Clipper Mapping Imaging Spectrometer For Europa (Mise): 
Using Compositional Mapping To Understand Europa, 50th Lunar and Planetary Science Conference 2019 (LPI Contrib. No. 2132), abstract 2218

Brissaud, O., B. Schmitt, N. Bonnefoy, S. Douté, P. Rabou, W. Grundy, and M. Fily 2004. Spectrogonio radiometer for the study of the bidirectional reflectance and polarization functions of planetary surfaces: I. Design and tests. Appl. Optics, 43 (9), 1926-1937

Brueckner, J.; Karunatillake, S.; Hamara, D.; Boynton, W. V., 2009. Sulfur concentrations of the Martian surface derived from orbital Mars Odyssey GRS and in-situ MER APXS measurements: implications on the selection of future landing sites, American Geophysical Union, Fall Meeting 2009, abstract id.P43D-1457

Carlson, R.W., Johnson, R.E., Anderson, M.S., 1999. Sulfuric acid on Europa and the radiolytic sulfur cycle. Science 286 (5437), 97-99. DOI: 10.1126/science.286.5437.97.

Carlson, R.W., Calvin, W.M., Dalton, J.B., Hansen, G. B., Hudson, R. L., Johnson, R. E., McCord, T. B., Moore, M.H.: Europa's Surface Composition, Europa, Edited by R.T. Pappalardo, W.B. McKinnon, K.K. Khurana. University of Arizona Press, Tucson. The University of Arizona space science series ISBN: 9780816528448, p.283, 2009

Christy A.G.: Sulfate Minerals. In: White W.M. (eds) Encyclopedia of Geochemistry. Encyclopedia of Earth Sciences Series. Springer, Cham, 2018

Clark R.N. and Roush T.L.: Reflectance Spectroscopy: Quantitative Analysis Techniques for Remote Sensing Applications, Journal of Geophysical Research, vol.89, n.B7, pp.6329-6340, 1984

Clark, R.N., King, T.V.V., Klejwa, M., Swayze, G., 1990. High spectral resolution reflectance spectroscopy of minerals. Journal of Geophysical Research 95 (B8), 1265312680

Cloutis E.A., Frank C. Hawthorne, Stanley A. Mertzman, Katherine Krenn, Michael A. Craig, Dionne Marcino, Michelle Methot, Johnathon Strong, John F. Mustard, Diana L. Blaney, James F. Bell III, Faith Vilas: Detection and discrimination of sulfate minerals using reflectance spectroscopy, Icarus 184, 121-157, 2006

Crowley J.K.: Visible and Near-Infrared (0.4-2.5 um) Reflectance Spectra of Playa Evaporite Minerals, Journal of Geophysical Research, vol. 96, No. B10, pages 16,231$16,240,1991$

Dalton J.B., Prieto-Ballesteros O., Kargel J.S., Jamieson C.S., Jolivet J., Quinn R.: Spectral comparison of heavily hydrated salts with disrupted terrains on Europa. Icarus 177, 472-490, 2005

Dalton, J.B., 2007. Linear mixture modeling of Europa's non-ice material based on cryogenic laboratory spectroscopy. Geophys. Res. Lett. 34 (21), L21205.

De Angelis, S., Carli, C., Tosi, F., Beck, P., Schmitt, B., Piccioni, G., De Sanctis, M.C., Capaccioni, F., Di lorio, T., Philippe, S., 2017. Temperature-dependent VNIR spectroscopy of hydrated Mg-sulfates. Icarus 281, 444-458. DOI: 10.1016/j.icarus.2016.07.022. 
De Angelis, Simone; Tosi, Federico; Carli, Cristian; Beck, Pierre; Brissaud, Olivier; Schmitt, Bernard (2018a): VNIR reflectance spectra of Thénardite $\left(\mathrm{Na}_{2} \mathrm{SO}_{4}\right)$ with 3 different grain sizes and at variable temperature (80-304K). SSHADE/REFL_SLAB+CSS (OSUG Data Center). Dataset/Spectral - Data. https://doi.org/10.26302/SSHADE/EXPERIMENT_CC_20180427_001

De Angelis, Simone; Tosi, Federico; Carli, Cristian; Beck, Pierre; Brissaud, Olivier; Schmitt, Bernard (2018b): VNIR reflectance spectra of Mirabilite $\left(\mathrm{Na}_{2} \mathrm{SO}_{4} \cdot 10 \mathrm{H}_{2} \mathrm{O}\right)$ with 3 different grain sizes and at variable temperature (80-298K). SSHADE/REFL_SLAB+CSS (OSUG Data Center). Dataset/Spectral Data. https://doi.org/10.26302/SSHADE/EXPERIMENT_CC_20180428_002

De Angelis, S., Carli, C., Tosi, F., Beck, P., Brissaud, O., Schmitt, B., Potin, S., De Sanctis, M.C., Capaccioni, F., Piccioni, G., 2019. NIR reflectance spectroscopy of hydrated and anhydrous sodium carbonates at different temperatures. Icarus 317, 388-411. DOI: 10.1016/j.icarus.2018.08.012.

De Sanctis M.C., Altieri F., Ammannito E., Biondi D., De Angelis S., Meini M., Mondello G., Novi S., Paolinetti R., Soldani M., Mugnuolo R., Pirrotta S., Vago J.L., and the Ma_MISS team, 2017. Ma_MISS on ExoMars: Mineralogical Characterization of the Martian Subsurface, Astrobiology Volume 17, Numbers 6 and 7, 2017 a Mary Ann Liebert, Inc., ExoMars Rover Mission, DOI: 10.1089/ast.2016.1541

Eugster H.P.: Geochemistry of Evaporitic Lacustrine Deposits, Annual Review of Earth and Planetary Science, 8, 35-63, 1980

Flahaut J., M. Massé, L. Le Deit, P.Thollot, J.-P. Bibring, F. Poulet, C. Quantin, N. Mangold, J. Michalski and J. L. Bishop, 2014. Sulfate-Rich Deposits On Mars: A Review Of Their Occurrences And Geochemical Implications, $8^{\text {th }}$ International Conference on Mars, abs.\#1196, 2014

Flahaut J., M. Martinot, J.L. Bishop, G.R. Davies, N.J. Potts: Remote sensing and in situ mineralogic survey of the Chilean salars: An analog to Mars evaporite deposits? Icarus 282, 152-173, 2017

Foley C.N., T. Economou, and R.N. Clayton: Final chemical results from the Mars Pathfinder alpha proton X-ray spectrometer, Journal Of Geophysical Research, VOL. 108, NO. E12, 8096, doi:10.1029/2002JE002019, 2003

Gendrin A. N. Mangold, J-P. Bibring, Y. Langevin, B. Gondet, F. Poulet, G. Bonello, C. Quantin, J. Mustard, R. Arvidson, S. LeMouelic: Sulfates in Martian Layered Terrains: The OMEGA/Mars Express View, Science 307, 1587; DOI: 10.1126/science.1109087, 2005

Grisolle F. (2013). Les condensats saisonniers de Mars : étude expérimentale de la formation et du métamorphisme de glaces de CO2. PhD thesis, Université Joseph Fourier, Grenoble. [TEL: https://tel.archives-ouvertes.fr/tel-01167247/document]

Grundy W.M. and Schmitt B.: The temperature-dependent near-infrared absorption spectrum of hexagonal H2O ice. Journal of Geophysical Research, vol. 103, N. E11, pp. 25,809-25,822, 1998 
Hapke, B., 1993. Theory of Reflectance and Emittance Spectroscopy. Cambridge University Press, p. 455. http://dx.doi.org/10.1017/CBO9780511524998. Online ISBN 9780511524998

Hardie L.A. and H.P. Eugster: The evolution of closed-basin brines, Mineralogical Society of America Spec. Pap., 3, 273-290, 1970

Harloff J. and Arnold G., 2001. Near-infrared reflectance spectroscopy of bulk analog materials for planetary crust. Planetary and Space Science 49, 191-211

Herrero M.J., J.I. Escavy, and B.C. Schreiber: Thénardite after mirabilite deposits as a cool climate indicator in the geological record: lower Miocene of central Spain, Clim. Past, 11, 1-13, www.clim-past.net/11/1/2015/doi:10.5194/cp-11-1-2015, 2015

Jones, B.F. and Deocampo, D.M: Geochemistry of Saline Lakes. Treatise on Geochemistry, Chapter 5.13, 393-424, 2003

Korablev O.I., Dobrolensky Y., Evdokimova N., Fedorova A.A., Kuzmin R.O., Mantsevich S.N., Cloutis E.A., Carter J., Poulet F., Flahaut J., Griffiths A., Gunn M., Schmitz N., Martìn-Torres J., Zorzano M.P., Rodionov D.S., Vago J.L., Stepanov A.V., Titov A.Y., Vyazovetsky N.A., Trokhimovskiy A.Y., Sapgir A.G., Kalinnikov Y.K., Ivanov Y.S., Shapkin A.A., Ivanov A.Y., 2017. Infrared Spectrometer for ExoMars: A Mast-Mounted Instrument for the Rover, Astrobiology Volume 17, Number 6 and 7, 2017 a Mary Ann Liebert, Inc., ExoMars Rover Mission, DOI: 10.1089/ast.2016.1543

Kuzmin R.O., P.R. Christensen, and M. Yu. Zolotov: Global Mapping Of Martian Bound Water At 6.1 Microns Based On Tes Data: Seasonal Hydration-Dehydration Of Surface Minerals, 35th Lunar and Planetary Science Conference, abstract LPSC-\#1810, 2004

Ligier, N., Poulet, F., Carter, J., Brunetto, R., Gourgeot, F., 2016. VLT/SINFONI Observations of Europa: New Insights into the Surface Composition. The Astronomical Journal, Volume 151, Issue 6, article id. 163. DOI: 10.3847/0004-6256/151/6/163.

Ligier, N., Paranicas, C., Carter, J., Poulet, F., Calvin, W.M., Nordheim, T.A., Snodgrass, C., Ferellec, L., 2019. Surface composition and properties of Ganymede: Updates from ground-based observations with the near-infrared imaging spectrometer SINFONINLT/ESO. Icarus 333, 496-515. DOI: 10.1016/j.icarus.2019.06.013.

Mangold N., A. Gendrin, B. Gondet, S. LeMouelic, C. Quantin, V. Ansan, J-P. Bibring, Y. Langevin, P. Masson, G. Neukum: Spectral and geological study of the sulfate-rich region of West Candor Chasma, Mars, Icarus 194, 519-543, 2008

McCord, T.B., Hansen, G.B., Clark, R.N., Martin, P.D., Hibbitts, C.A., Fanale, F.P., Granahan, J.C., Segura, M., Matson, D.L., Johnson, T.V., Carlson, R.W., Smythe, W.D., Danielson, G.E., and the NIMS team, 1998a. Non-water ice constituents in the surface material of the icy Galilean satellites from the Galileo near-infrared mapping spectrometer investigation. J. Geophys. Res. 103, n E4, 8603-8626. 
McCord T.B., Hansen G.B., Fanale F.P., Carlson R.W., Matson D.L., Johnson T.V., Smythe W.D., Crowley J.K., Martin P.D., Ocampo A., Hibbitts C.A., Granahan J.C., and the Galileo NIMS team: Salts on Europa's Surface Detected by Galileo's Near Infrared Mapping Spectrometer. Science, 280, pp. 1242-1245, DOI: 10.1126/science.280.5367.1242, 1998b

McCord T.B., Hansen G.B., Matson D.L., Johnson T.V., Crowley J.K., Fanale F.P., Carlson R.W., Smythe W.D., Martin P.D., Hibbitts C.A., Granahan J.C., and Ocampo A.: Hydrated salt minerals on Europa's Surface from the Galileo near-infrared mapping spectrometer (NIMS) investigation. Journal of Geophysical Research, vol. 104, No. E5, pages 11,827-11,851, 1999

McCord T.B., Orlando T.M., Teeter G., Hansen G.B., Sieger M.T., Petrik N.G. and Van Keulen L.: Thermal and radiation stability of the hydrated salt minerals epsomite, mirabilite, and natron under Europa environmental conditions. Journal of Geophysical Research, vol. 106, No. E2, pages 3311-3319, 2001

McCord, T.B., Teeter, G., Hansen, G.B., Sieger, M.T., Orlando, T.M., 2002. Brines exposed to Europa surface conditions. J. Geophys. Res. (Planets) 107 (E1), CitelD 5004, DOI: 10.1029/2000JE001453.

McCord T.B., Hansen G.B., Combe J.-P., Hayne P.: Hydrated minerals on Europa's surface: An improved look from the Galileo NIMS investigation. Icarus, 209, 639-650, 2010

Murchie S.L., J.F. Mustard, B.L. Ehlmann, R.E. Milliken, J.L. Bishop, N.K. McKeown, E.Z. Noe Dobrea, F.P. Seelos, D.L. Buczkowski, S.M. Wiseman, R.E. Arvidson, J.J. Wray, G. Swayze, R.N. Clark, D.J. Des Marais, A.S. McEwen, and J-P. Bibring: A synthesis of Martian aqueous mineralogy after 1 Mars year of observations from the Mars Reconnaissance Orbiter, Journal Of Geophysical Research, VOL. 114, E00D06, doi:10.1029/2009JE003342, 2009

Omori K. and P.F. Kerr: Infrared studies of saline sulfate minerals, Geological Society of America Bulletin; 74, n.6; 709-734, doi: 10.1130/0016-7606, 1963

Paganini, L., Villanueva, G.L., Roth, L., Mandell, A.M., Hurford, T.A., Retherford, K.D., Mumma, M.J., 2020. A measurement of water vapour amid a largely quiescent environment on Europa. Nature Astronomy 4, 266-272. DOI: 10.1038/s41550-019-0933-6.

Piccioni, G., Tommasi, L., Langevin, Y., Filacchione, G., et al., 2019. Scientific goals and technical challenges of the MAJIS imaging spectrometer for the JUICE mission. Proceedings of the 2019 IEEE 5th International Workshop on Metrology for AeroSpace, Turin (Italy), 19-21 June 2019. DOI: 10.1109/MetroAeroSpace.2019.8869566.

Roth, L., Saur, J., Retherford, K.D., Strobel, D.F., et al., 2014. Transient Water Vapor at Europa's South Pole. Science 343, 171-174, doi: 10.1126/science.1247051.

Shirley, J.H., Dalton, J.B., Prockter, L.M., Kamp, L.W., 2010. Europa's ridged plains and smooth low albedo plains: Distinctive compositions and compositional gradients at the leading side-trailing side boundary. Icarus 210 (1), 358-384. DOI: 10.1016/j.icarus.2010.06.018. 
Pommerol, A., B. Schmitt, P. Beck, and O. Brissaud 2009. Water sorption on Martian regolith analogs: thermodynamics and near-infrared reflectance spectroscopy. Icarus, 204, 114-136.

Potin, S., Brissaud, O., Beck P., Schmitt, B., Magnard, Y., Correia, J-J., Rabou, P., And Jocou L.: SHADOWS: a spectro-gonio radiometer for bidirectional reflectance studies of dark meteorites and terrestrial analogs: design, calibrations, and performances on challenging surfaces, Applied Optics, vol 57, n.28, pp 8279-8296, 2018

Rice, M. S., Bell III, J. F., Cloutis, E. A., Wang, A., Ruff, S. W., Craig, M. A., Bailey, D. T., Johnson, J. R., de Souza Jr., P. A., Farrand, W. H., 2010. Silica-rich deposits and hydrated minerals at Gusev Crater, Mars: Vis-NIR spectral characterization and regional mapping. Icarus. 205, 375-395.

Salisbury J.W. and Walter L.S.: Thermal Infrared (2.5-13.5 $\mu \mathrm{m})$ Spectroscopic Remote Sensing of Igneous Rock Types on Particulate Planetary Surfaces, Journal of Geophysical Research, vol.94, n.B7, 9192-9202, 1989

Socki R.A., T. Sun, P.B. Niles, R.P. Harvey, D.L. Bish, and E. Tonui: Antarctic Mirabilite Mounds As Mars Analogs: The Lewis Cliffs Ice Tongue Revisited, 43rd Lunar and Planetary Science Conference, abstract LPSC-\#2718, 2012

Sparks, W.B., Hand, K. P., McGrath, M.A., Bergeron, E., et al., 2016. Probing for evidence of plumes on Europa with HST/STIS. Astrophys. J. 829,121, DOI: 10.3847/0004$637 X / 829 / 2 / 121$.

Steiger, M., Asmussen, S. 2008. Crystallization of sodium sulfate phases in porous materials: The phase diagram $\mathrm{Na}_{2} \mathrm{SO}_{4}-\mathrm{H}_{2} \mathrm{O}$ and the generation of stress. Geochimica et Cosmochimica Acta 72, 4291-4306, doi:10.1016/j.gca.2008.05.053

Thomas E.C., Hodyss R., Vu T.H., Johnson P.V., and Choukroun M., 2017. Composition and Evolution of Frozen Chloride Brines under the Surface Conditions of Europa, ACS Earth and Space Chemistry, 1, 14-23, DOI: 10.1021/acsearthspacechem.6b00003

Tosca N.J. and McLennan S.M., 2006. Chemical divides and evaporite assemblages on Mars, Earth and Planetary Science Letters 241, 21-31

Trumbo, S.K., Brown, M.E., Hand, K.P., 2019. Sodium chloride on the surface of Europa. Science 5 (6), id. aaw7123. DOI: 10.1126/sciadv.aaw7123.

Vassallo A.M. and Finnie K.S. : Infrared Emission Spectroscopy of Some Sulfate Minerals, Applied Spectrosopy, vol.46, n.10, 1992

Vu T.H., Hodyss R., Choukroun M., and Johnson P.V.: CHEMISTRY OF FROZEN SODIUM-MAGNESIUM-SULFATE-CHLORIDE BRINES: IMPLICATIONS FOR SURFACE EXPRESSION OF EUROPA'S OCEAN COMPOSITION, The Astrophysical Journal Letters, 816:L26 (6pp), doi:10.3847/2041-8205/816/2/L26, 2016

Warren, J.: Evaporites: Sediments, Resources and Hydrocarbons, Springer, Berlin, 2006 
Zolotov M.Y., R.O. Kuzmin and E.L. Shock: Mineralogy, Abundance, And Hydration State Of Sulfates And Chlorides At The Mars Pathfinder Landing Site, 35th Lunar and Planetary Science Conference, abstract LPSC-\#1465, 2004 